\title{
Activity of Insula to Basolateral Amygdala Projecting Neurons is Necessary and Sufficient for Taste Valence Representation
}

\author{
${ }^{\circ}$ Haneen Kayyal, ${ }^{1 *}$ () Adonis Yiannakas, ${ }^{1 *}$ (DSailendrakumar Kolatt Chandran, ${ }^{1}$ Mohammad Khamaisy, ${ }^{1}$ \\ Vijendra Sharma, ${ }^{1}$ and $\odot$ Kobi Rosenblum ${ }^{1,2}$ \\ ${ }^{1}$ Sagol Department of Neuroscience, and ${ }^{2}$ Center for Gene Manipulation in the Brain, University of Haifa, Mount Carmel, Haifa, 3498838, Israel
}

Conditioned taste aversion (CTA) is an associative learning paradigm, wherein consumption of an appetitive tastant (e.g., saccharin) is paired to the administration of a malaise-inducing agent, such as intraperitoneal injection of LiCl. Aversive taste learning and retrieval require neuronal activity within the anterior insula (aIC) and the basolateral amygdala (BLA). Here, we labeled neurons of the aIC projecting to the BLA in adult male mice using a retro-AAV construct and assessed their necessity in aversive and appetitive taste learning. By restricting the expression of chemogenetic receptors in aIC-to-BLA neurons, we demonstrate that activity within the aICto-BLA projection is necessary for both aversive taste memory acquisition and retrieval, but not for its maintenance, nor its extinction. Moreover, inhibition of the projection did not affect incidental taste learning per se, but effectively suppressed aversive taste memory retrieval when applied either during or before the encoding of the unconditioned stimulus for CTA (i.e., malaise). Remarkably, activation of the projection after novel taste consumption, without experiencing any internal discomfort, was sufficient to form an artificial aversive taste memory, resulting in strong aversive behavior upon retrieval. Our results indicate that aIC-to-BLA projecting neurons are an essential component in the ability of the brain to associate taste sensory stimuli with body states of negative valence and guide the expression of valence-specific behavior upon taste memory retrieval.

Key words: amygdala; brain circuits; insula; memory; taste learning; valence encoding

Significance Statement

In the present study we subjected mice to the conditioned taste aversion paradigm, where animals learn to associate novel taste with malaise (i.e., assign it negative valence). We show that activation of neurons in the anterior insular cortex (aIC) that project into the basolateral amygdala (BLA) in response to conditioned taste aversion is necessary to form a memory for a taste of negative valence. Moreover, artificial activation of this pathway (without any feeling of pain) after the sampling of a taste can also lead to such associative memory. Thus, activation of aIC-to-BLA projecting neurons is necessary and sufficient to form and retrieve aversive taste memory.

\section{Introduction}

The anterior insular cortex (aIC) plays a crucial role in taste learning (Rosenblum, 2008) and self-referential processes shap-

Received April 3, 2019; revised Sept. 12, 2019; accepted Sept. 17, 2019.

Author contributions: H.K., A.Y., and K.R. designed research; H.K., A.Y., S.K.C., M.K., and V.S. performed research; H.K., A.Y., S.K.C., M.K., and V.S. analyzed data; H.K. and A.Y. wrote the first draft of the paper; K.R. edited the paper; K.R. wrote the paper.

This work was supported by a grant from the Canadian Institutes of Health Research (CIHR), the International Development Research Centre (IDRC), the Israel Science Foundation (ISF), and the Azrieli Foundation (ISF-IDRC 2395/2015); ISF 946/17; ISF-UGC 2311/15; and ChromlSyn ERANET Neuron II supported by the Israel Ministry of Health Grant 3-12492 to K.R. H.K. is a recipient of the Edmond de Rothschild's scholarship. We thank the members of the K.R. laboratory, specifically Dr. Shunit Gal Ben-Ari, for critical reading of this manuscript.

The authors declare no competing financial interests.

*H.K. and A.Y. contributed equally to this work. ing conscious awareness in humans (Craig, 2009). Furthermore, it likely promotes circuit-wide dysfunction in neuropsychiatric disorders (Caria et al., 2010; Kurth et al., 2010; Critchley and Seth, 2012; Pais-Vieira et al., 2016). Nonetheless, the robust nature of taste learning paradigms, as well as their proven dependence on activity at the region, have made the aIC a particularly reliable target in studies of the molecular and cellular mechanisms underlying taste learning and memory (Bures et al., 1998; Belelovsky et al., 2005; Merhav et al., 2006; Yefet et al., 2006; Bermudez-

V. Sharma's present address: Department of Biochemistry and Goodman Cancer Centre, McGill University, 1160 Pine Ave. W., Montreal QC H3A 1A3, Canada.

Correspondence should be addressed to Kobi Rosenblum at kobir@psy.haifa.ac.il.

https://doi.org/10.1523/JNEUROSCI.0752-19.2019

Copyright $\odot 2019$ the authors 
Rattoni, 2014). Administration of a malaise-inducing agent (e.g., $\mathrm{LiCl}$ ) after the consumption of appetitive tastants, results in conditioned taste aversion (CTA), through the association of the conditioned stimulus (CS) with the negative consequences of the unconditioned stimulus (US) (Garcia et al., 1955; Rosenblum et al., 1993).

CTA learning and retrieval is subserved by the gustatory cortex, located within the aIC (Lin et al., 2015), composed of granular (GI), dysgranular (DI), and agranular (AI) subregions, arranged in the dorsoventral plane (Kosar et al., 1986; Yiannakas and Rosenblum, 2017). Integration of sensory and reward stimuli is thought to be facilitated by reciprocal interactions with the limbic system (Krushel and van Der Kooy, 1988), the thalamus (Cechetto and Saper, 1987), as well as the basolateral and central amygdala (Grossman et al., 2008; Moraga-Amaro and Stehberg, 2012). The basolateral amygdala in particular is known to be required for stimulus salience encoding (Fontanini and Katz, 2009), as well as generating and relaying palatability signals to the IC (Piette et al., 2012). Correlative studies have suggested that connectivity between the aIC and the basolateral amygdala (BLA) facilitates the encoding and retrieval of sensory information in relation to body states, shaping their perceived valence (Gogolla, 2017; Haley and Maffei, 2018; Tye, 2018). In agreement with the above, we have shown recently that recruitment of IC neurons projecting to the BLA is increased during the retrieval of aversive taste memories, in a valence-, but not stimulus-dependent manner (Lavi et al., 2018). Despite providing evidence of high temporal precision in vivo, the methodology involved is correlative by its nature. We thus attempted here to address whether activation of the IC-to-BLA projection is necessary and/or sufficient for the expression of learned aversive taste experiences. Toward this aim, first, wild-type (WT) were injected bilaterally with a retrograde-adeno-associated virus 2 (retroAAV) construct at the BLA, labeling monosynaptic anterograde connections of the IC with the BLA (Tervo et al., 2016). We analyzed the connectivity of aIC to BLA comparing dorsal-ventral, anterior-posterior and inner versus outer cortical layers (see Fig. 1). To test the necessity of this projection in aversive taste memory learning, retrieval and maintenance (see Figs. 3, 4, 5, 6), we stereotactically injected mice with appropriate AAV constructs resulting in chemogenetic silencing or activation of IC-to-BLA projecting neurons (see Fig. 2 ), using administration of the synthetic ligand Clozapine- $\mathrm{N}$ oxide (CNO) locally or peripherally (Gomez et al., 2017). Our results indicate that recruitment of IC-to-BLA projecting neurons is an essential component in the ability of the brain to associate taste sensory stimuli with body states of negative valence and retrieve such aversive memories.

\section{Materials and Methods}

Animals

Wild-type (WT) adult male mice (8-12 weeks) were used in all experiments described (Envigo). All mice used for the purposes of these studies were housed in the local Animal Resource Unit with water and standard chow pellet available ad libitum, under a $12 \mathrm{~h}$ dark/light cycle, except where stated. All procedures were approved by the institutional animal care and use committee in accordance with the University of Haifa regulations and National Institutes of Health Guidelines, under Ethical License $428 / 16$

\section{Surgery and viral injection}

Adult (8-12 weeks old) male WT mice were used as specified. Animals were administered an intraperitoneal injection of the analgesic Norocarp $(0.5 \mathrm{mg} / \mathrm{kg}), 30 \mathrm{~min}$ before being anesthetized using a suitable M3000 anesthetic machine (NBT Israel/Scivena Scientific) using isoflurane
(5\%). After the induction of anesthesia, animals were quickly adjusted to a Model 963 Kopf Instruments stereotaxic injection system, where anesthesia was similarly maintained using isoflurane (2\%). After exposure of the skull and relevant alignment, mice were injected with appropriate AAV constructs at the anterior agranular insula (AP +0.86; ML \pm 3.4 ; $\mathrm{DV}-4.00)$ and/or the basolateral amygdala (AP -1.6 ; $\mathrm{ML} \pm 3.375$; DV -4.80 ) as specified in each experiment (Tervo et al., 2016). In a separate cohort of mice, after bilateral stereotactic injection of AAV constructs at both regions, guide steel cannulas (23gauge) were inserted $1 \mathrm{~mm}$ above the aIC, to allow local delivery of CNO upon recovery. Cannula placement was secured using dental cement as previously described (Alapin et al., 2018). After viral delivery and appropriate cleaning and suturing (Vetbond) of the exposed skull, animals were administered an additional intraperitoneal dose of $0.5 \mathrm{mg} / \mathrm{kg}$ Norocarp, as well as $0.5 \mathrm{mg} / \mathrm{kg}$ Baytril (enrofloxacin). Animals were allowed an initial $2 \mathrm{~h}$ to recover in an appropriately clean and heat-adjusted cage, and were then housed in larger cages with similarly treated cage-mates. Similar weight adjusted doses of the said analgesic and antibiotic agents were administered for an additional $3 \mathrm{~d}$ after recovery. All animals were allowed 3 weeks of recovery in their home cages. During the fourth week of recovery, animals were transferred to individual cages for $5 \mathrm{~d}$, in preparation for water restriction training as described below.

All AAV constructs used in this study were obtained from the viral vector facility of the University of Zurich (http://www.vvf.uzh.ch). All mice used in our studies were injected with $0.25 \mu \mathrm{l} / \mathrm{site} / \mathrm{h}$ emisphere of said AAV constructs (physical titer $=4.5 \times 10 \mathrm{E} 12 \mathrm{vg} / \mathrm{ml}$ ) as defined in each experiment.

\section{Immunohistochemistry and quantification (see Fig. 1)}

Brain tissue was incubated for $24 \mathrm{~h}$ in $4 \%$ formaldehyde solution, followed by $48 \mathrm{~h}$ in 30\% sucrose in PBS (PBS, MFCD00131855, SigmaAldrich). Tissue was subsequently frozen at $-80^{\circ} \mathrm{C}$ and processed for slicing using a cryostat (Leica CM 1950). Twenty-four $40-\mu$ m-thick brain slices were collected between bregma 1.18 and 0.26 , and treated for fluorescent immunohistochemistry. Immediately after slicing, tissue was briefly washed in PBS, before blocking and permeabilization for $1 \mathrm{~h}$ using a $0.3 \%$ bovine serum albumin (10775835001, Sigma-Aldrich) $/ 0.3 \%$ Triton X-100 (MFCD00128254, Sigma-Aldrich)/10\% fetal bovine serum solution (MFCD00132239, Sigma-Aldrich) in PBS (blocking solution). Slices were washed and mounted on glass slides using Vectashield mounting medium with DAPI (H-1200) or without (H-1000), depending on whether EBFP-expressing AAVs were used (Vector Laboratories Cat\# H-1200 and H-1000, RRID:AB_2336790 and AB_2336789). Slides were visualized using a vertical light microscope (Olympus CellSens Dimension) at $10 \times$ and $20 \times$ magnification. Images were processed using Image-Pro Plus V-7, Media Cybernetics and manually quantified in terms of total numbers retroAAV ${ }^{+}$neurons in the respective subregions and layers of the aIC. Data were subsequently analyzed in terms of the bilateral number of positive cells/slice using 2-way ANOVA (GraphPad Prism).

Behavioral procedures (see Figs. 3, 4, 5, 6):

In experiments involving chemogenetic inhibition of the IC-BLA projection, we bilaterally injected WT male mice into the IC with a Cre-dependent AAV construct expressing the inhibitory DREADD receptor in neurons, AAV8_hEFla-dlox-hM4D (Gi) _mCherry (rev)dlox-WPRE-hGHp (A) (Addgene plasmid \#50461; http://n2t.net/ addgene:50461; RRID:Addgene_50461). To direct expression of the DREADD receptor into IC-BLA projecting neurons, retroAAV-hSyn1chI-EBFP2_2A_iCre-WPRE-SV40p (A) or retroAAV-hSyn1-chI-EGFP2 2A_iCre-WPRE-SV40p (A) was injected at the BLA (Addgene plasmid \#81070; http://n2t.net/addgene:81070; RRID:Addgene_81070).

Similarly, in experiments involving chemogenetic activation of the IC-BLA projection, we bilaterally injected WT male mice with a Credependent AAV construct expressing excitatory DREADD receptors in neurons of the IC, through AAV8_hEF1a-dlox-hM3D (Gq) _mCherry (rev)-dlox-WPRE-hGHp (A) (Addgene plasmid \#44361; http://n2t.net/ addgene:44361; RRID:Addgene_44361). DREADD receptor expression was restricted to the IC-BLA projecting neurons, by injecting retroAAV- 
hSyn1-chI-EBFP2_2A_iCre-WPRE-SV40p (A) or retroAAV-hSyn1-chIEGFP2_2A_iCre-WPRE-SV40p (A) at the BLA (Addgene plasmid \#81070; http://n2t.net/addgene:81070; RRID:Addgene_81070).

For CTA acquisition, mice having recovered from surgery, received 1 $\mathrm{ml}$ of $0.5 \%$ saccharin- or $0.5 \% \mathrm{NaCl}$-water after $4 \mathrm{~d}$ of water restriction training (Adaikkan and Rosenblum, 2015). Forty minutes after the start of the $20 \mathrm{~min}$ drinking session (interstimulus interval, ISI $=40 \mathrm{~min}$ ), animals were intraperitoneally injected with a $2 \%$ body weight dose of the malaise inducing agent $\mathrm{LiCl}(0.14 \mathrm{M})$, the US. For the subsequent $2 \mathrm{~d}$, mice were maintained under water restriction. Three days after CTA acquisition, mice were provided with a choice between the conditioned tastant and tap water. Aversion to the conditioned tastant was calculated by expressing the volume of water consumed as a percentage of the total intake (water and tastant). Doses of CNO used in all experiments were chosen based on recent publications demonstrating that higher chronic doses of the ligand are metabolized into clozapine, which can affect behavior in itself (Gomez et al., 2017).

\section{IC-BLA projection inhibition during CTA acquisition or retrieval, systemic CNO administration (see Fig. $3 A-D$ )}

During CTA Acquisition, mice received CNO $(0.5 \mathrm{mg} / \mathrm{kg}$, i.p.) (Enzo, http://www.enzolifesciences.com/BML-NS105/clozapine-N-oxide/) 30 min before CTA training for saccharin $(0.5 \%)$. Mice were provided a choice test between the conditioned tastant and water during retrieval testing $3 \mathrm{~d}$ later. To examine the effect of circuit inhibition during CTA retrieval, mice were trained in $\mathrm{CTA}$ for $\mathrm{NaCl}(0.5 \%)$. Three days later mice received $0.5 \mathrm{mg} / \mathrm{kg} \mathrm{CNO} 40 \mathrm{~min}$ before retrieval testing. In both experiments, control mice received weight matched (1\% body weight) injections of saline at the same intervals.

A separate group of mice were trained in CTA for saccharin as described above, and underwent chemogenetic inhibition of the IC-BLA projection during retrieval. After the retrieval session, mice were used to examine the effect of circuit inhibition during retrieval on the subsequent extinction of the CTA memory using 9 unreinforced choice tests between the CS and water.

\section{IC-BLA projection inhibition during CTA acquisition or retrieval, Local CNO Administration (see Fig. 5E-I)}

Mice underwent surgery to place aIC cannulas allowing for the local inhibition of the aIC-to-BLA projection. Based on the current literature, mice received $0.25 \mu \mathrm{l}$ of $10 \mu \mathrm{M} \mathrm{CNO} /$ site, at a speed of $0.1 \mu \mathrm{l} / \mathrm{min}$, dissolved in artificial CSF (ACSF), or a similar volume of the vehicle (Burnett and Krashes, 2016). Delivery cannulas were secured as to allow mice to freely move during delivery without affecting the procedure. Mice treated during CTA acquisition received CNO or ACSF immediately before being presented with $1 \mathrm{ml}$ of $0.5 \% \mathrm{NaCl}$ for $20 \mathrm{~min}$. Immediately after the drinking session, mice received a $2 \%$ body weight dose of $\mathrm{LiCl}$ and were returned to their cages. Three days later, mice were tested using a 20 min choice test between $\mathrm{NaCl}$ and water. Mice were then allowed an additional $3 \mathrm{~d}$ of recovery and the groups were reversed, so that the same mice did not receive $\mathrm{CNO}$ twice. Mice treated through cannulas during CTA retrieval, acquired CTA for 0.5\% Saccharin and were similarly tested $72 \mathrm{~h}$ after conditioning, receiving CNO or ACSF 15 min prior (Adaikkan and Rosenblum, 2015).

\section{IC-BLA projection inhibition during CTA memory maintenance (see Fig. 2E,F)}

After recovery and water restriction training, adult male mice were randomly assigned to CNO- and saline-treated groups and underwent CTA training for saccharin $(0.5 \%)$. Mice in the treatment group were administered CNO $(0.5 \mathrm{mg} / \mathrm{kg}$, i.p.) $24 \mathrm{~h}$ after CTA training ( $2 \%$ body weight $\mathrm{LiCl}(0.14 \mathrm{~m}$, i.p.), ISI $=40 \mathrm{~min})$ using $1 \mathrm{ml}$ of the saccharin solution, while the control group received an intraperitoneal injection of saline ( $1 \%$ body weight). Animals were maintained on water restriction for an additional $48 \mathrm{~h}$, followed by a choice test between the CS and tap water.

CNO control studies (see Fig. 5A-D)

Mice were injected with retroAAV2_hSyn1- $\chi$-EGFP_2A_iCre-WPRESV40P (A) at the BLA and AAV8_hEFla-dlox-mCherry (rev)-dloxWPRE-hGHp (A) at the aIC. After 4 weeks of recovery mice were administered $1 \mathrm{mg} / \mathrm{kg}$ CNO $30 \mathrm{~min}$ before CTA training, as described above. Mice were similarly examined using a choice test between the CS $(0.5 \% \mathrm{NaCl})$ and water, $3 \mathrm{~d}$ later. After a week of recovery, mice acquired CTA for a second tastant (0.5\% Saccharin). Mice received CNO $40 \mathrm{~min}$ before a choice test between the CS and water, as described above. To confirm the validity of our approach using $\mathrm{CNO}$ in different phases of CTA acquisition (see Figs. 3, 4), an additional cohort of 8 animals was treated with retroAAV2_hSyn1- $\chi$-EGFP_2A_iCre-WPRE-SV40P (A) at the BLA and AAV8_hEF1a-dlox-mCherry (rev)-dlox-WPRE-hGHp (A) at the aIC. After 4 weeks of recovery mice were administered CNO $(0.5$ $\mathrm{mg} / \mathrm{kg}$, i.p.) $1 \mathrm{~h}$ before the start of a $20 \mathrm{~min}$ exposure to $1 \mathrm{ml}$ of $0.5 \%$ saccharin, while the control group received an intraperitoneal injection of saline ( $1 \%$ body weight). Three hours later, both groups were administered a $2 \%$ body weight injection of $\mathrm{LiCl}$. Mice were provided with a choice test between the conditioned tastant and tap water, $3 \mathrm{~d}$ later. After an additional a week of recovery, the groups were reversed, so that the same mice did not receive CNO twice. Two hours after the start of a 20 min exposure to $1 \mathrm{ml}$ of the saccharin water, half of the cohort received a similar dose of $\mathrm{CNO}$, while the control group received an intraperitoneal injection of saline ( $1 \%$ body weight). Three hours from the start of drinking, both groups were administered a $2 \%$ body weight injection of $\mathrm{LiCl}$.

Additional control studies were conducted in un-injected adult $(8-12$ weeks) WT male mice. These mice were water restricted for $5 \mathrm{~d}$ before CTA training for saccharin using $0.14 \mathrm{M} \mathrm{LiCl}$ at ISI $=40$, as described in previous sections. Three days later, mice were given a choice test between pipettes containing the conditioned tastant and water, for $20 \mathrm{~min}$. Fortyfive minutes before retrieval testing, half of the conditioned animals received $\mathrm{CNO}(1 \mathrm{mg} / \mathrm{kg}$, i.p.), while the rest received a $1 \%$ body weight injection of saline.

\section{IC-BLA projection inhibition before novel taste learning and attenuation of neophobia (see Fig. 4A,B)}

After surgery recovery, we separated mice into two groups (CNO and saline). Mice in the treatment group were administered CNO $(1 \mathrm{mg} / \mathrm{kg}$, i.p.), while the control group received an intraperitoneal injection of saline ( $1 \%$ body weight), $1 \mathrm{~h}$ before a choice test between $0.5 \%$ saccharin and tap water. The above choice test was repeated for another $2 \mathrm{~d}$, without any intraperitoneal injections. Drinking volumes were recorded and relevant behavioral measures were calculated and analyzed.

\section{IC-BLA projection inhibition before novel innately aversive} taste exposure

We randomly assigned mice into two groups (CNO and saline) after surgery recovery. After $4 \mathrm{~d}$ of water restriction training, mice in the treatment group were administered CNO $(1 \mathrm{mg} / \mathrm{kg}$, i.p.) $1 \mathrm{~h}$ before a choice test between $0.04 \%$ quinine and water. Conversely the control group received an intraperitoneal injection of saline ( $1 \%$ body weight), before the choice test. Drinking volumes were recorded and relevant behavioral measures were calculated and analyzed.

IC-BLA projection inhibition during CS encoding (see Fig. 3C,D) Adult male mice randomly assigned to the treatment group were administered CNO $(0.5 \mathrm{mg} / \mathrm{kg}$, i.p.) $1 \mathrm{~h}$ before the start of a $20 \mathrm{~min}$ exposure to $1 \mathrm{ml}$ of the saccharin water, while the control group received an intraperitoneal injection of saline ( $1 \%$ body weight). Three hours later, both groups were administered a $2 \%$ body weight injection of $\mathrm{LiCl}(0.14 \mathrm{M}$, i.p.). Mice were provided with a choice test between the conditioned tastant and tap water, $3 \mathrm{~d}$ later.

\section{IC-BLA projection inhibition during US encoding (see Fig. $3 E, F$ )} Mice in the treatment group were administered CNO (0.5 mg/kg, i.p.) $2 \mathrm{~h}$ after to the start of a 20 min exposure to $1 \mathrm{ml}$ of the saccharin water, while the control group received an intraperitoneal injection of saline $(1 \%$ body weight). Three hours from the start of drinking, both groups were administered a $2 \%$ body weight injection of $\mathrm{LiCl}(0.14 \mathrm{~m}$, i.p.). After an additional $48 \mathrm{~h}$ on water restriction, mice were provided with a choice test between the conditioned tastant and tap water. Drinking volumes were recorded, and relevant behavioral measures were calculated and analyzed. 


\section{IC-BLA projection inhibition during the retrieval of trace fear} conditioning (see Fig. 4G,H)

Mice were allowed 4 weeks of recovery and were subsequently randomly allocated into two groups (CNO and saline), without being isolated from their cage-mates. Animals were tested in the subsequent $2 \mathrm{~d}$ were trained using trace fear conditioning (Curzon et al., 2009). Twenty-four hours after training, mice were tested for contextual fear conditioning, being returned to the training chamber, where their activity was recorded for $180 \mathrm{~s}$ without the tone. On the following day, mice in the treatment group were administered $\mathrm{CNO}(0.5 \mathrm{mg} / \mathrm{kg}$, i.p.) $45 \mathrm{~min}$ before the start of the retrieval session, while the control group received an intraperitoneal injection of saline ( $1 \%$ body weight). Behavior was recorded, and relevant measures were calculated and analyzed (Freeze Frame; Coulbourn Instruments).

\section{IC-BLA projection activation during weak CTA conditioning (see Fig. 6A,B)}

After recovery and isolation, mice were allocated into two groups, which after $4 \mathrm{~d}$ of water restriction training were provided $1 \mathrm{ml}$ of $0.5 \% \mathrm{NaCl}$ solution. Mice in the treatment group were administered $\mathrm{CNO}(1 \mathrm{mg} / \mathrm{kg}$, i.p.) $30 \mathrm{~min}$ before weak CTA conditioning $(0.07 \mathrm{M} \mathrm{LiCl})$ while the control group received an intraperitoneal injection of saline (1\% body weight). Three days later, mice in both groups were provided with a choice test between the conditioned tastant and tap water.

\section{IC-BLA projection activation after novel taste learning \\ (see Fig. 6C,D)}

Mice were allocated into two groups, which after $4 \mathrm{~d}$ of water restriction training were provided $1 \mathrm{ml}$ of $0.5 \%$ saccharin solution. Mice in the treatment group were administered CNO intraperitoneal $(1 \mathrm{mg} / \mathrm{kg}) 10$ min after the end of drinking session, while the control group received an intraperitoneal injection of saline ( $1 \%$ body weight). Mice in both groups were provided with a choice test between $0.5 \%$ saccharin-water and tap water, after an additional $48 \mathrm{~h}$ of water restriction. Drinking volumes were recorded, and relevant behavioral measures were calculated and analyzed.

\section{IC-BLA projection activation during CTA memory maintenance} (see Fig. 6F, G)

Mice in the treatment group were administered CNO (1 mg/kg. i.p.), $24 \mathrm{~h}$ after weak CTA training ( $2 \%$ body weight $\mathrm{LiCl}(0.075 \mathrm{M}$, i.p. $)$, ISI $=40$ $\mathrm{min}$ ) using $1 \mathrm{ml}$ of the saccharin water, while the control group received an intraperitoneal injection of saline ( $2 \%$ body weight). Animals were maintained on water restriction for an additional $48 \mathrm{~h}$, before a choice test. Drinking volumes were recorded, and relevant behavioral measures were calculated and analyzed.

Electrophysiology (see Fig. 2)

Insula slice preparations. Mice were injected with retroAAV2 hSyn1- $\chi$-EGFP_2A_iCre-WPRE-SV40P(A) at the BLA and AAV8_ hSyn 1-dlox-hM3D(Gq)_mCherry(rev)-dlox-WPRE-hGHp(A) or AAV8_hEF1a-dlox-hM4D(Gi)_mCherry(rev)-dlox-WPRE-hGHp(A) at the aIC. To obtain brain slices containing insula, mice were deeply anesthetized with $5 \%$ isoflurane and transcardially perfused with $40 \mathrm{ml}$ of ice-cold oxygenated cutting solution containing the following (in $\mathrm{mm}$ ): $25 \mathrm{NaHCO}_{3}, 105$ Choline-Chloride, $2.5 \mathrm{KCl}, 7 \mathrm{MgCl}_{2}, 0.5 \mathrm{CaCl}_{2}, 1.25$ $\mathrm{NaH}_{2} \mathrm{PO}_{4}, 25$ D-glucose, $1 \mathrm{Na}$-Ascorbate and $3 \mathrm{Na}$-Pyruvate. All reagents were commercially obtained from Sigma-Aldrich Israel, except where stated. The 300- $\mu \mathrm{m}$-thick coronal brain slices were cut with a Campden-1000 Vibrotome using the same cutting solution. The slices were incubated for at least $60 \mathrm{~min}$ at $34^{\circ} \mathrm{C}$ in artificial CSF (ACSF) containing the following (in $\mathrm{mm}$ ): $125 \mathrm{NaCl}, 25 \mathrm{NaHCO}_{3}, 2.5 \mathrm{KCl}, 1.25$ $\mathrm{NaH}_{2} \mathrm{PO}_{4}, 2 \mathrm{CaCl}_{2}, 1 \mathrm{MgCl}_{2}$ and $25 \mathrm{D}$-glucose, before transferring them to the electrophysiological setup. For electrophysiological recordings, slices were placed in an ACSF-perfused recording chamber $(2 \mathrm{ml} / \mathrm{min}$, $\left.32-34^{\circ} \mathrm{C}\right)$. All solutions were constantly carbogenated with carbogen $\left(95 \% \mathrm{O}_{2}+5 \% \mathrm{CO}_{2}\right)$.

Whole-cell recording. The slices were illuminated with infrared light, and pyramidal cells were visualized under differential interference contrast microscope (DIC) with $\times 40$, water-immersion objective mounted on a fixed-stage microscope (BX51-WI; Olympus). BLA-projecting neurons of the IC expressing the chemogenetic hM4DGi or hM3DGq receptors in a Cre-dependent manner were identified by the presence of mCherry. Cells projecting to the BLA that did not express the chemogenetic receptors were identified using GFP. Whole-cell recordings from double fluorescence-labeled cells were performed using an Axopatch 200B amplifier and digitized by Digidata 1440 (Molecular Devices). The recording electrode was pulled from a borosilicate glass pipette (3-5 $\mathrm{M} \Omega$ ) using an electrode puller (P-1000; Sutter Instruments) and filled with a K-gluconate-based internal solution (in $\mathrm{mm}$ ): $130 \mathrm{~K}$-gluconate, 5 $\mathrm{KCl}, 10$ HEPES, $2.5 \mathrm{MgCl}_{2}$, 0.6 EGTA, $4 \mathrm{Mg}$-ATP, $0.4 \mathrm{Na}_{3}$ GTP and 10 phosphocreatine ( $\mathrm{Na}$ salt). The osmolarity was $290 \mathrm{mOsm}$, and $\mathrm{pH}$ was 7.3. The recording glass pipettes were patched onto the soma region of pyramidal cells (Sharma et al., 2018). Voltages for liquid junction potential $(+10 \mathrm{mV})$ were not corrected online. Current-clamp recordings were low-pass filtered at $10 \mathrm{kHz}$ and sampled at $20 \mathrm{kHz}$. Series resistance was compensated and only series resistance $<20 \mathrm{M} \Omega$ was included in the dataset. Pipette capacitance was $\sim 80 \%$ compensated. After $3-5$ min stable baseline recording, $\mathrm{CNO}(2-10 \mu \mathrm{M})$ was added to the ASCF solution containing antagonist mixture of (DNQX $(20 \mu \mathrm{M})$; APV (50 $\mu \mathrm{M})$; bicuculline methiodide (20 $\mu \mathrm{M})$, CAS40709-69-1, Tocris Bioscience), was applied through the bath to the brain slice to isolate postsynaptic effects. This was followed by normal ACSF application for 5-30 min or until significant recovery in membrane activity was observed. The changes in resting membrane potential were measured $1 \mathrm{~min}$ after $\mathrm{CNO}$ application (Nakajima et al., 2016).

\section{Results}

\section{Majority of IC-to-BLA projecting neurons reside in the AI and DI subregions}

To examine the role of IC-BLA projecting neurons in taste valence encoding, we first measured the differential neuroanatomical connectivity between the different subregions of the aIC and the BLA using injection of an retroAAV2 construct at the BLA, allowing the labeling of BLA-projecting neurons of the aIC (Fig. $1 A ; n=11)$. Quantification of mCherry ${ }^{+}$neurons of the aIC was used to assess the efficiency and distribution of the retroAAV2 construct to label BLA-projecting neurons.

Approximately $5 \%$ of all the cells of the superficial or deep layers of the aIC are BLA projecting neurons. Approximately $62 \%$ of the BLA projecting neurons identified across the aIC reside within deep layers IV-VI rather than the superficial layers (Fig. $\left.1 B ; F_{(1,168)}=27.14, p<0.0001\right)$. This effect was prominent in the posterior part across the bregma axis (Fig. $1 B ; F_{(3,168)}=2.825$, $p=0.04)$. The majority of BLA-projecting neurons in the superficial (Fig. $1 C ; F_{(2,252)}=173.2, p<0.0001$ ) and deep layers IV-VI (Fig. $1 D ; F_{(6,252)}=6.303, p<0.0001$ ) of the aIC reside in the AI $(48 \%)$ and DI (39\%), while a smaller proportion reside at the GI (13\%).

Unlike the DI and GI, BLA-projecting neurons in the superficial AI decrease in abundance from bregma 0.86 onwards (Fig. $\left.1 C ; F_{(3,252)}=4.498, p=0.0043\right)$. In parallel, the number of BLA-projecting neurons is increased in the posterior part of the deep layers of the DI (Fig. $1 D ; F_{(3,252)}=4.213, p=0.0063$ ). In the deep layers of the AI, the number of BLA-projecting neurons rapidly declines from bregma 0.86 onward (Fig. $1 D ; F_{(6,252)}=$ 6.303, $p<0.0001)$.

\section{Activity in BLA-projecting neurons of the aIC can be chemogenetically manipulated using the retroAAV system}

To test the functionality of this projection, we injected both retroAAV2_hSyn1_EGFP_iCre at the BLA, and Cre-dependent, AAV8_hEF1 $\alpha$-driven constructs at the IC to restrict the expression of chemogenetic receptors (hM4DGi or hM3DGq) in aIC-to-BLA neurons (see Materials and Methods). Whole-cell 


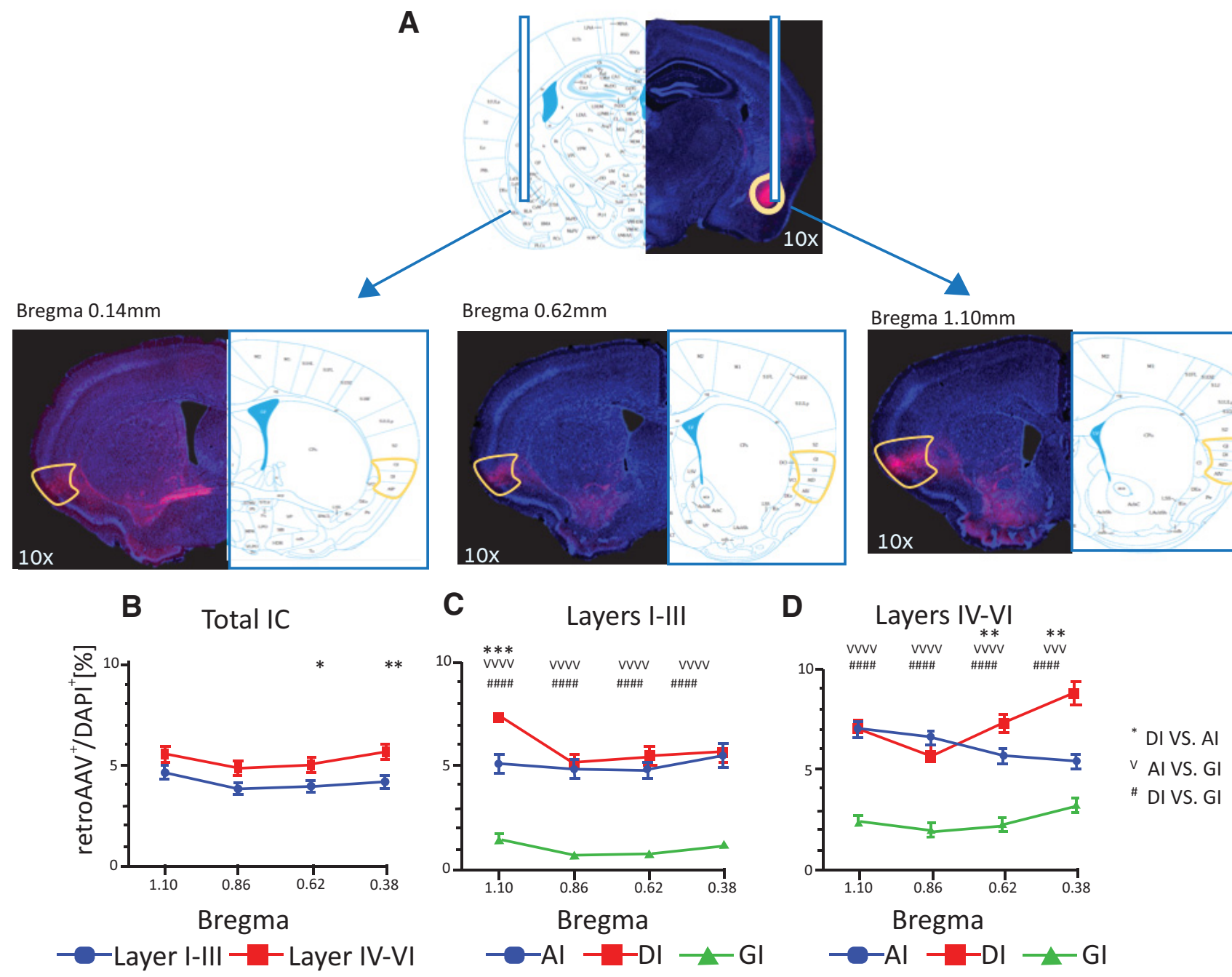

Figure 1. The majority of IC-to-BLA projecting neurons reside in the Al and DI subregions. BLA-projecting neurons of the alC were labeled using a retroAAV2_hSyn_mCherry construct, and their distribution was quantified in the different spatial dimensions of the alC across 24 coronal slices of the mouse brain $(A)$. The average number of BLA-projecting neurons/slice in superficial layers I-III and deep layers IV-VI of the alC, were plotted in relation to the bregma axis and as percentage of number of DAPI + cells ( $\boldsymbol{B}$ ). Analysis of the distribution using two-way ANOVA, indicated that a higher proportion of $B L A-$ projecting neurons resided in deep layers $(\boldsymbol{B})$ than in superficial layers, an effect that was observed at bregma 0.62 and 0.38 across the axis $(\boldsymbol{B})$. The percentage of $B L A-p r o j e c t i n g$ neurons in superficial layers $(\boldsymbol{C})$, of the Al and the DI surpassed the numbers observed in the $\mathrm{Gl}$, across the bregma axis $(\boldsymbol{C}$ ). Higher number of BLA-projecting neurons of the Al was observed at 1.10 of the bregma axis compared with the $\mathrm{DI}(\boldsymbol{C})$. Similarly, in deep layers (D), the percentages of BLA-projecting neurons in the Al and DI (D) were higher compared with the GI. In the DI, the number of BLA-projecting neurons tended to increase across the rostro-caudal axis (D), while it was decreased in the Al. ${ }^{*} p \leq 0.05,{ }^{* *} p \leq 0.01,{ }^{* * *} p \leq 0.001,{ }^{\text {vvv }} p \leq 0.0001$, ${ }^{\# \# \# \#} p \leq 0.0001$.

patch-clamp recordings in slices from BLA-projecting neurons of the aIC confirmed that bath application of CNO $(10 \mu \mathrm{M})$ rapidly hyperpolarized the resting membrane potentials (Wilcoxon test, $Z=-21.00, p=0.0313$ ) and inhibited the activity of neurons expressing hM4DGi-mCherry ${ }^{+}$(Fig. $\left.2 A, E, F\right)$, but not in the hM4DGi-mCherry $^{-}$or $\mathrm{GFP}^{+}$expressing control cells (Fig. $2 C, I, J$, Wilcoxon test, $Z=-7.00, p=0.3750)$. Similarly, in slices from mice treated to express hM3DGq in aIC-to-BLA neurons, bath application of CNO $(2 \mu \mathrm{M})$ rapidly depolarized the resting membrane potentials (Wilcoxon test, $Z=21.00, p=0.0313$ ) and increased action potential firing in neurons expressing hM3DGqmCherry $^{+}$(Fig. 2 B, G,H), but not in the hM3DGq-mCherry ${ }^{-}$or $\mathrm{GFP}^{+}$controls (Fig. 2D,K,L, Wilcoxon test, $Z=0.00$, $p<$ $0.9999)$.

IC-to-BLA projecting neurons are necessary for the acquisition and retrieval but not for the extinction or maintenance of learned aversive memories

Inhibition of aIC-to-BLA projecting neurons using $\mathrm{CNO}$ during CTA acquisition suppressed the aversive response (76.07 \pm
$5.42 \%, n=8$ ) compared with control animals (Fig. $3 B, C$, $93.00 \pm 2.76 \%, n=6$, unpaired $t$ test, $p=0.0276, t=2.507$, $\mathrm{DF}=12$ ). Significant suppression of the aversive response was also observed in comparing animals that acquired CTA normally $(81.90 \pm 6.64, n=6)$, to ones that experienced inhibition $(47.74 \pm 11.06 \%, n=7)$ of the projection during retrieval (Fig. $3 D, E$, unpaired $t$ test, $p=0.0278, t=2.533$, DF $=11$ ).

This latter treatment did not affect the subsequent extinction of this aversive memory (Fig. $3 H, I, p=0.9327, F_{(1,24)}=$ $0.007284)$. Treated mice $(88.04 \pm 3.996 \%, n=7)$ exhibited similar aversion to control mice $(93.04 \pm 5.329 \%, n=7) 1 \mathrm{~d}$ after the retrieval. After 14 unreinforced choice tests between water and saccharin, control $(57.30 \pm 11.69 \%, p=0.0166)$ and IC-BLA inhibited $(63.70 \pm 9.389 \%, p=0.0344)$ mice exhibited similar extinction over time (repeated-measures ANOVA, $F_{(13,156)}=$ 8.514, $p<0.0001)$, but no significant effect of treatment was observed $\left(F_{(1,13)}=0.3314, p=0.5747\right)$. Similarly, inhibition of the projection during intervals associated with memory maintenance after conditioning (Fig. $3 F, G$ ) resulted in similar aversion 
Inhibitory DREADDs

A

Cre+hM4Di CNO 10 uM

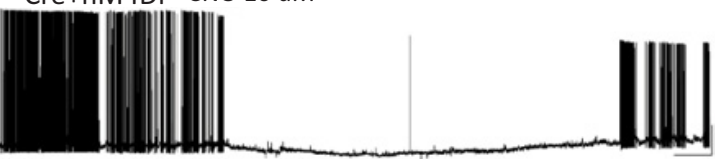

$-50 m V$

C

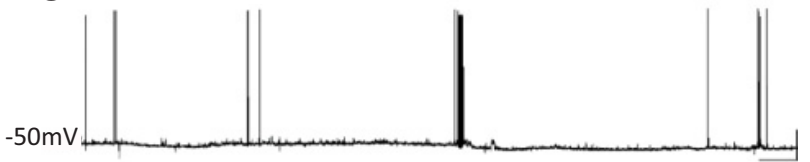

B

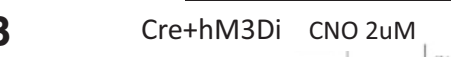

$-72 m V$

D

$-72 m V$
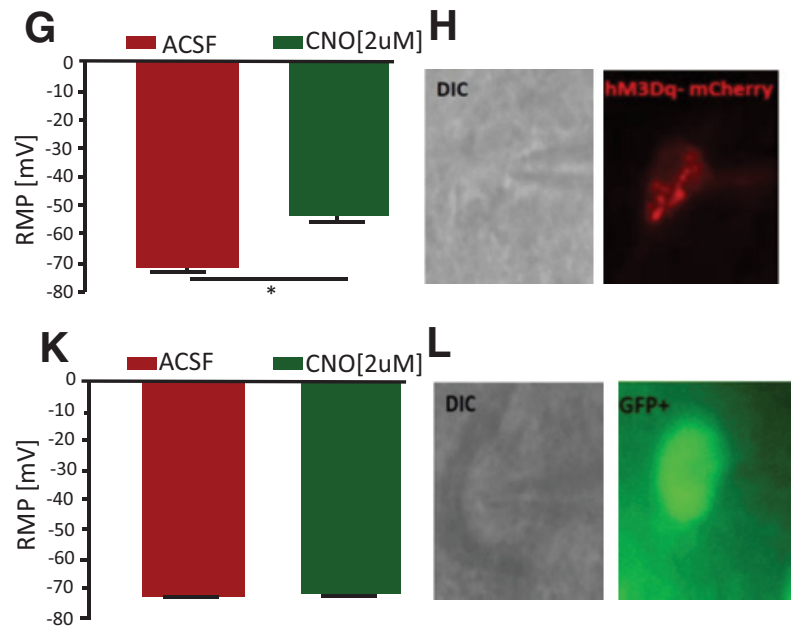

Excitatory DREADDs

Cre+hM3Di CNO 2uM

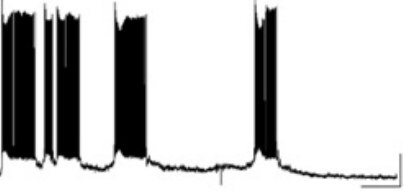

$\mathrm{GFP}^{+} \mathrm{CNO} 2 \mathrm{UM}$
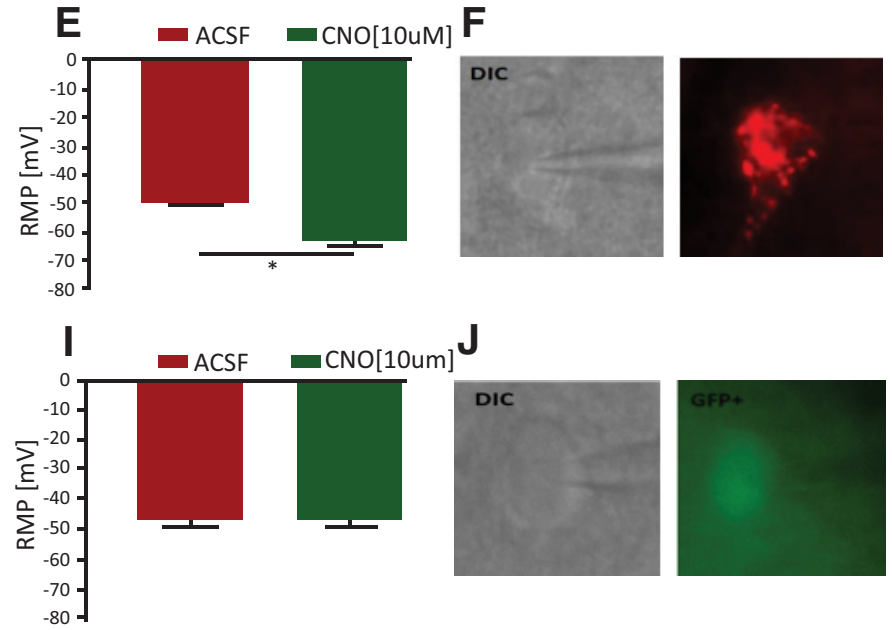

Figure 2. Activity in BLA-projecting neurons of the alC can be chemogenetically manipulated using the retroAAV system. Using dual viral injections at the two regions (See Materials and Methods), we restricted the expression of chemogenetic receptors in IC-to-BLA projecting neurons in a Cre-dependent fashion $(\boldsymbol{A}-\boldsymbol{L})$. Whole-cell current-clamp recordings of $\mathrm{mCherry}{ }^{+} \mathrm{hM} 4 \mathrm{DG} \mathrm{i}^{+}$ IC neurons projecting to BLA $(\boldsymbol{F})$, showed rapid hyperpolarization of membrane potentials and reduced firing rates after the application of $10 \mu \mathrm{M}(\mathrm{NO}$ for 60 s in the bath $(\boldsymbol{A})$. Example traces from 5 similar recordings $\left(n=6\right.$ cells from 5 mice) from mCherry ${ }^{+} \mathrm{hM} 4 \mathrm{DGi}{ }^{+}$neurons projecting from the IC to the BLA (A). Unlike responses to $10 \mu \mathrm{M}$ CN0 application in mCherry ${ }^{+}$hM4DGi ${ }^{+}$cells, non-hM4DGi expressing (mCherry-) EGFP ${ }^{+}$neurons $(\boldsymbol{J})$, did not show any change in membrane potential $\left(C, n=4\right.$ from 4 mice). Whole-cell current-clamp recording of mCherry ${ }^{+}$hM3DG ${ }^{+}$ neurons in the insula projecting to BLA $(\boldsymbol{H})$, showed rapid depolarization of membrane potentials and increased firing rates after the application of $2 \mu \mathrm{M}$ CNO in the bath for $60 \mathrm{~s}$ ( $\mathrm{B}, n=6$ cells from 5 mice). Unlike responses to $2 \mu \mathrm{m}$ CNO application in mCherry ${ }^{+} \mathrm{hM} 3 \mathrm{DGq}+$ cells, non-hM3DGq expressing (mCherry $\left.{ }^{-}\right)$EGFP ${ }^{+}$neurons $(\boldsymbol{L})$, did not show any change in membrane potential $(\mathrm{D}, n=$ 4 from 4 mice). Measurement of resting membrane potential changes in DREADD and non-DREADD-expressing cells, before and after the application CN0, showed a significant change in the RMP of DREADD-expressing cells after the application of CN0, inhibitory and activator DREADD respectively $(\boldsymbol{E}, \boldsymbol{G}, n=6)$. There was no change in the RMP of non- DREADD expressing control cells before and after the application of CNO $(\boldsymbol{I}, \boldsymbol{K})$, inhibitory and activator DREADD respectively $(n=4)$. Scale bars in the traces $(\boldsymbol{A}-\boldsymbol{D})$ represent $20 \mathrm{mV}(y$-axis $)$ and $1 \mathrm{~min}\left(\boldsymbol{x}\right.$-axis). ${ }^{*} p \leq 0.05$.

(unpaired $t$ test, $p=0.8693, t=0.1681, \mathrm{DF}=12$ ) to the CS upon retrieval between treated $(92.01 \pm 3.924 \%, n=8)$ and control animals $(91.12 \pm 3.124 \%, n=6)$.

\section{Inhibition of IC-BLA-projecting neurons of the aIC disrupts} specifically CS-US association during CTA acquisition, but does not affect innate and appetitive taste behaviors

To test the role of the projection in innate taste behaviors, we examined the effect of inhibition during appetitive novel taste learning and how this subsequently affects the attenuation of neophobia (Fig. 4A). Mice were treated with $\mathrm{CNO}$ before exposure to a novel tastant and were choice tested for three consecutive days. Responses indicated a significant effect of taste exposure (Fig. $4 B$; repeated-measures ANOVA, $\left.F_{(2,38)}=68.92, p<0.0001\right)$ but not of treatment $\left(F_{(1,19)}=0.072, p=0.7915\right)$. Aversion to the tastant observed in the first session (AN1, saline $69.122 \pm$ $5.257 \%, n=10$; CNO $64.8 \pm 6.240 \%, n=11)$ was attenuated in the second (AN2, saline 38.231 $\pm 5.677 \%, n=10$; CNO $42.404 \pm$ $6.730 \%, n=11$ ) and third session (AN3, saline $23.442 \pm 7.914 \%$, $n=10$; CNO $30.113 \pm 6.160 \%, n=11)$. Aversion was significantly suppressed in AN2 compared with AN1, in both the CNO $(p=0.0001)$ and saline $(p<0.0001)$ groups. Aversion was also significantly suppressed in AN3 compared with AN2, in both the CNO $(p=0.0434)$ and saline $(p<0.0169)$ groups. We then tested whether inhibition of the projection affects aversion of innately aversive quinine by administering $\mathrm{CNO}$ or saline $1 \mathrm{~h}$ before a choice test between quinine and water (data not shown). Mice experiencing inhibition of the projection $(100 \pm 0 \%, n=6)$ and mice receiving saline $(99.02 \pm 2.405 \%, n=6)$, exhibited no significant differences in aversion to quinine (unpaired $t$ test, $p=$ $0.3409, t=1.000, \mathrm{DF}=10$ ).

To further examine whether the observed differences were due to taste recognition, we inhibited the projection before presenting the taste, and confined US association within the ICdependent $3 \mathrm{~h}$ margin (Adaikkan and Rosenblum, 2015). Projection inhibition during intervals associated with CS encoding affected the expression of aversion upon CTA retrieval when comparing saline $(87.18 \pm 4.432 \%, n=9)$ and $\mathrm{CNO}(65.63 \pm$ $7.167 \%, n=8$ ) treated animals (Fig. $4 C, D$, unpaired $t$ test, $p=$ $0.019, t=2.623, \mathrm{DF}=15$ ). Using the same rationale (Adaikkan and Rosenblum, 2015), we expanded the interstimulus interval and inhibited the projection before US administration (Fig. $4 E$ ). 


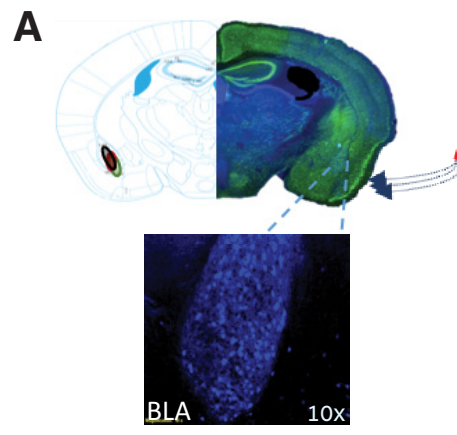

B

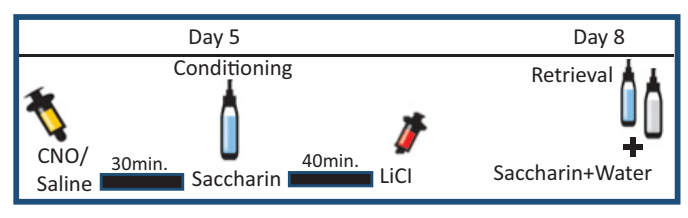

D

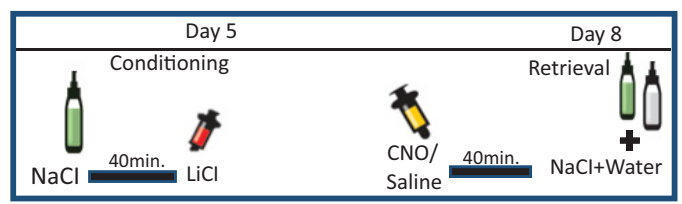

$\mathbf{F}$

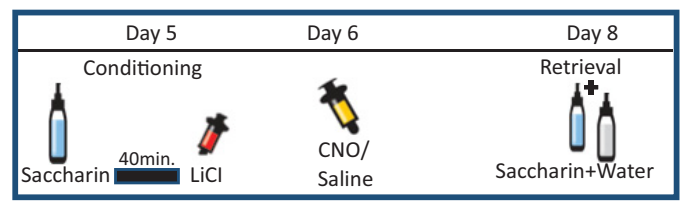

$\mathbf{H}$

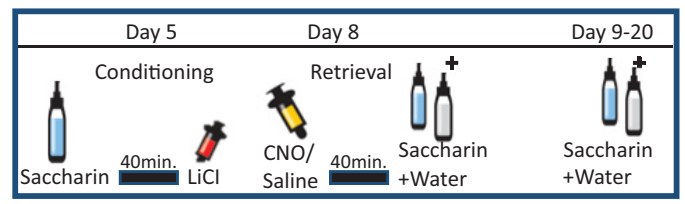

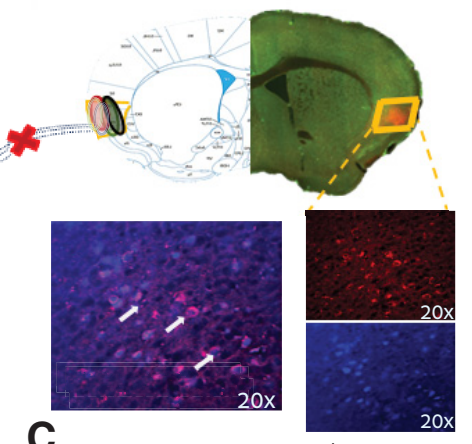

C
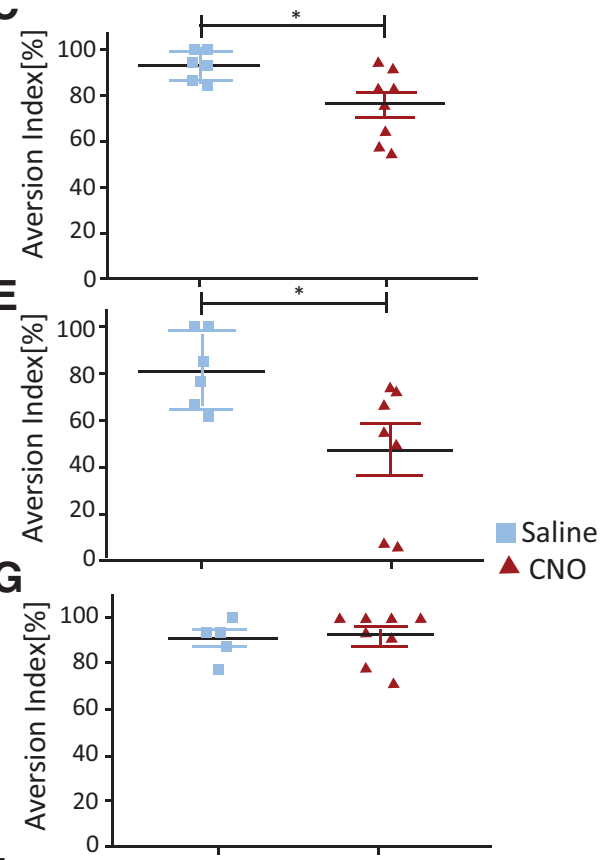

I

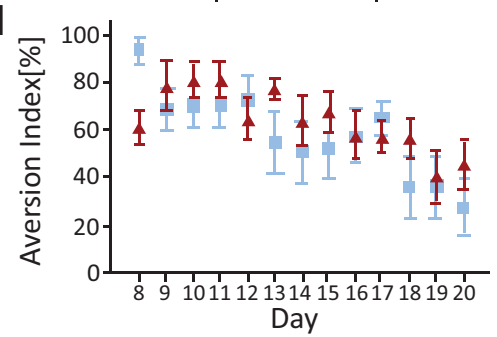

Figure 3. IC-to-BLA projecting neurons are necessary for the acquisition and retrieval but not for the extinction or maintenance of learned aversive memories. Adult (8-12 weeks) WT male mice were injected with viral constructs at the BLA (blue) and alC (red), resulting in expression of inhibitory hMD4Gi in alC-to-BLA neurons ( $A$ ). Representative schematic overlays of the Cre-dependent expression of the chemogenetic receptors using the retroAAV systems is shown, demonstrating the expression to be restricted in the BLA and alC ( $n=12$ slices). Animals were split into saline (light blue) and CNO (dark red) groups, and treated before CTA acquisition ( $\boldsymbol{B}$ ). Chemogenetic inhibition during (TA acquisition ( $\boldsymbol{C}$, significantly suppressed aversion upon retrieval compared with control animals (C). In separate experiments, similarly injected mice, were used to assess the role of the projection in (TA retrieval (D). Inhibition during (TA retrieval, significantly suppressed aversion compared with control animals $(\boldsymbol{E})$. To test whether the projection is also involved in CTA memory maintenance, we inhibited $24 \mathrm{~h}$ after acquisition, and proceeded to test the animals $48 \mathrm{~h}$ later $(\boldsymbol{F}$, G). Inhibition $24 \mathrm{~h}$ after conditioning, resulted in similar aversion upon retrieval testing in control and treated animals. Even though inhibition of the projection during the retrieval of CTA suppresses aversion to the $\mathrm{CS}(\boldsymbol{H}), 24 \mathrm{~h}$ later, treated mice $(\boldsymbol{I})$ exhibited similar aversion to control mice. After 14 unreinforced choice tests between water and saccharin, control and IC-BLA inhibited mice exhibited similar extinction of the conditioned response $(\boldsymbol{I})$ and no significant differences were observed among the two groups due to our intervention. ${ }^{*} p \leq 0.05$.

Similarly (Fig. 4F; unpaired $t$ test, $p=0.0016, t=3.686, \mathrm{DF}=$ 19), inhibition during US encoding for CTA suppressed aversion for the CS upon retrieval in CNO treated mice $(46.01 \pm 8.611 \%$, $n=11)$, but not in saline $(84.0 \pm 5.179 \%, n=10)$ treated mice.

We further show that inhibition of the projection before the retrieval of trace-fear conditioning does not affect freezing behavior (Fig. $4 G, H$ ), indicative of the specificity of this pathway for taste-malaise associations. Context testing resulted in similar freezing $\left(F_{(1,10)}=0.2873, p=0.6037\right)$ between the two groups. During the pretone, saline $(12.135 \pm 5.077 \%, n=5)$ and CNO $(13.693 \pm 1.834 \%, n=5)$ treated mice showed similar freezing $(p=0.4740)$. Tone (saline, $35.722 \pm 6.842 \%$; CNO, $37.910 \pm$ $8.565 \% ; p=0.7879$ ), and posttone (saline, $19.065 \pm 3.879 \%$; CNO, $17.713 \pm 6.208 \%$; $p=0.6753)$ intervals was similar between the two groups (2-way ANOVA, $F_{(1,8)}=0.004139, p=$ $0.9503)$. 

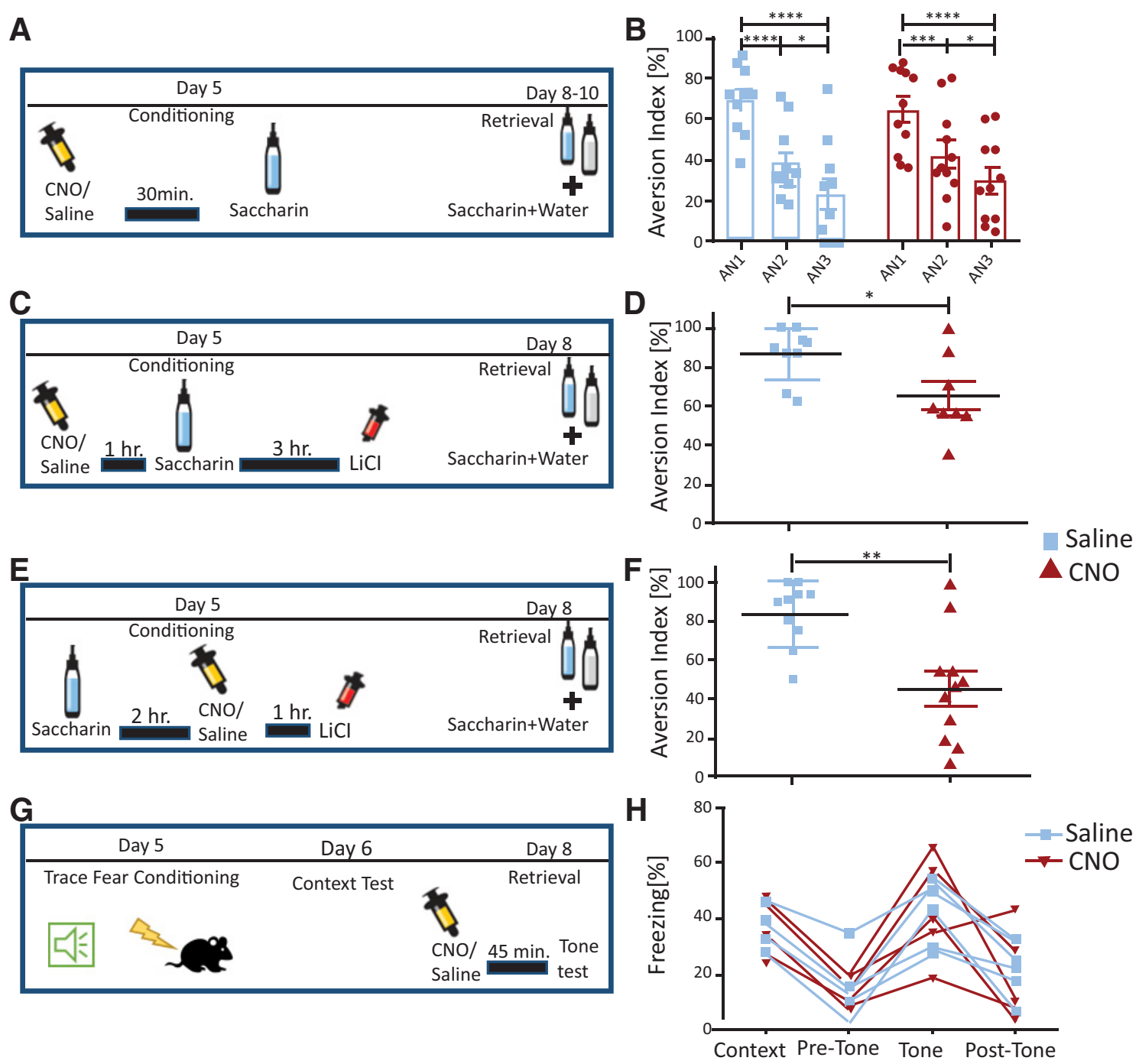

Figure 4. Inhibition of IC-BLA-projecting neurons of the alC are disrupts CS-US association during CTA acquisition, but does not affect innate taste behaviors. Attenuation of neophobia was assessed for $3 \mathrm{~d}$, in mice expressing hMD4Gi in alC-to-BLA neurons, receiving CNO (dark red) or saline (light blue) before novel saccharin consumption (A). Responses indicated a significant effect of taste exposure but not of treatment $(\boldsymbol{B})$. Aversion to the tastant observed in the first session was attenuated in the second and third session. Aversion was significantly suppressed in AN3 compared with AN1, in both the CNO and saline groups. Targeted inhibition of the CS for CTA (C) resulted in suppressed aversion upon retrieval in CN0 treated to saline groups $(\boldsymbol{D})$. Correspondingly, inhibition at intervals associated with US encoding $(\boldsymbol{E})$, resulted in significantly less aversion to the $C S$ in CNO, treated mice compared with controls $(\boldsymbol{F})$. A separate cohort of WT male mice treated to express hM4DGi in IC-to-BLA neurons, were trained in appropriate chambers to associate a tone to the administration of an electric shock using trace-fear conditioning (G). Mice were randomly split into two groups (CNO, dark red, saline, light blue) and were tested in the subsequent $48 \mathrm{~h}(\boldsymbol{G})$. The two groups exhibited similar levels of freezing during context testing $(\boldsymbol{H})$. On the following day, the $\mathrm{CNO}$ group received the artificial ligand $45 \mathrm{~min}$ before being placed in a different context, where the tone was presented (without shock) at time points identical to the conditioning trial $(\boldsymbol{G}, \boldsymbol{H})$. Freezing recorded during the pretone, tone, and posttone $(\boldsymbol{H})$ intervals was similar between the two groups. ${ }^{*} p \leq 0.05,{ }^{* *} p \leq 0.01,{ }^{* * *} p \leq 0.001,{ }^{* * * *} p \leq 0.0001$.

To account for any nonspecific effects of CNO administration (Gomez et al., 2017), we injected animals with AAV and retroAAV constructs at the IC and BLA, resulting in the expression of mCherry, without DREADD receptors. Behavioral experiments were conducted (Fig. 5A-C) as previously described (see Materials and Methods). Control virus treated mice receiving CNO $(n=5)$ and mice receiving saline $(n=6)$ before CTA acquisition or retrieval, exhibit no significant effect differences due to treatment (Fig. 5B, 2-way ANOVA, $F_{(1,18)}=0.03366, p=$ $0.8565)$, or as a consequence of the retrieval and acquisition protocols (Fig. $5 B, 2$-way ANOVA $(1,18)=1.887, p=0.1864$ ). Furthermore, toward assuring that the association in CS-and US experiments (Fig. $5 C, D$ ) was to the saccharin and not to the injection of $\mathrm{CNO}$, we repeated the experiments using control virusinjected mice. Our results indicate that CNO $(94.00 \pm 1.78 \%$, $n=4)$ and saline $(87.25 \pm 6.25 \%, n=4)$ treated mice show similar aversion to saccharin (Fig. $5 C, D, p=0.339, t=1.039$, $\mathrm{DF}=6)$, meaning that the aversion was not altered by the consecutive intraperitoneal injections or $\mathrm{CNO}$ administration itself. Similar result was observed in the protocol described for CS association (Fig. $5 C$ ), where CNO injected $(91.25 \pm 5.154 \%, n=4)$ and saline injected mice $(82.25 \pm 5.154 \%, n=4)$ showed similar aversion to saccharin $(p=0.4296, t=0.8468, \mathrm{DF}=6)$, which further strengthens our suggestion of specific association to gastric malaise caused by the LiCl.

To rule out the possibility that additional collaterals from the BLA mediate the effect we observed, we infused $\mathrm{CNO}$ locally via cannulas during CTA acquisition or retrieval (Fig. 5E). Steel guide cannulas where placed at the aIC in addition to the relevant injection of AAV and retroAAV at the aIC and BLA (see Materials and Methods). CNO or saline was infused before the conditioning or retrieval of CTA for salty or sweet taste (Fig. $5 F, G$ ). After 
A

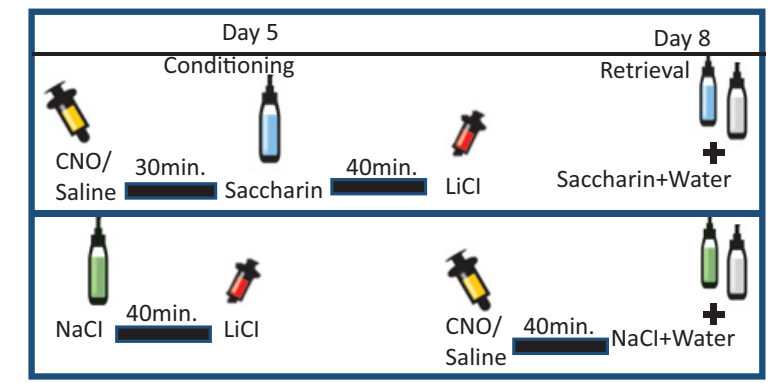

C

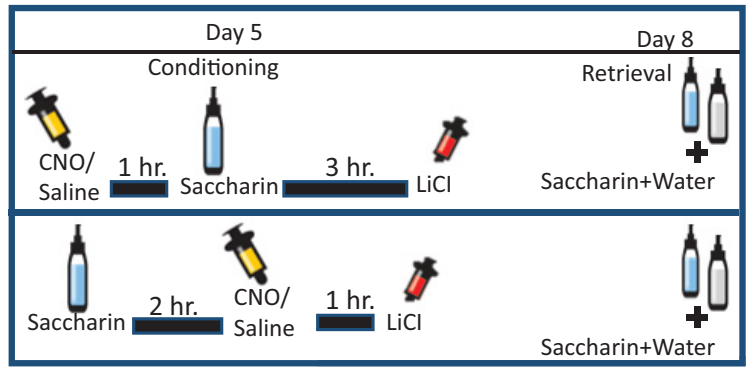

B

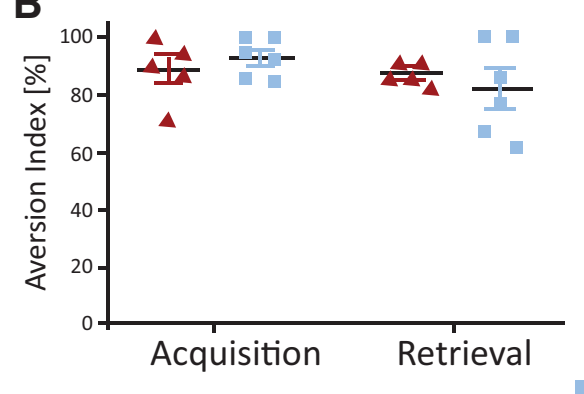

D

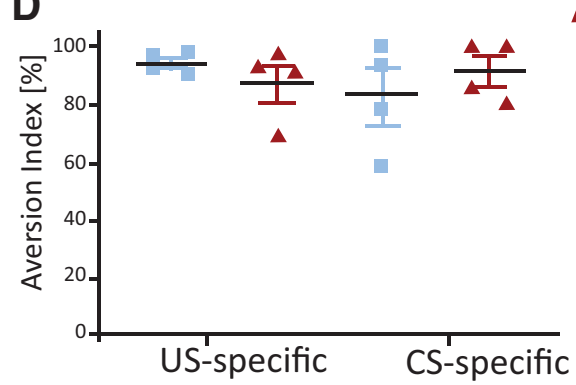

Saline

$\triangle \mathrm{CNO}$

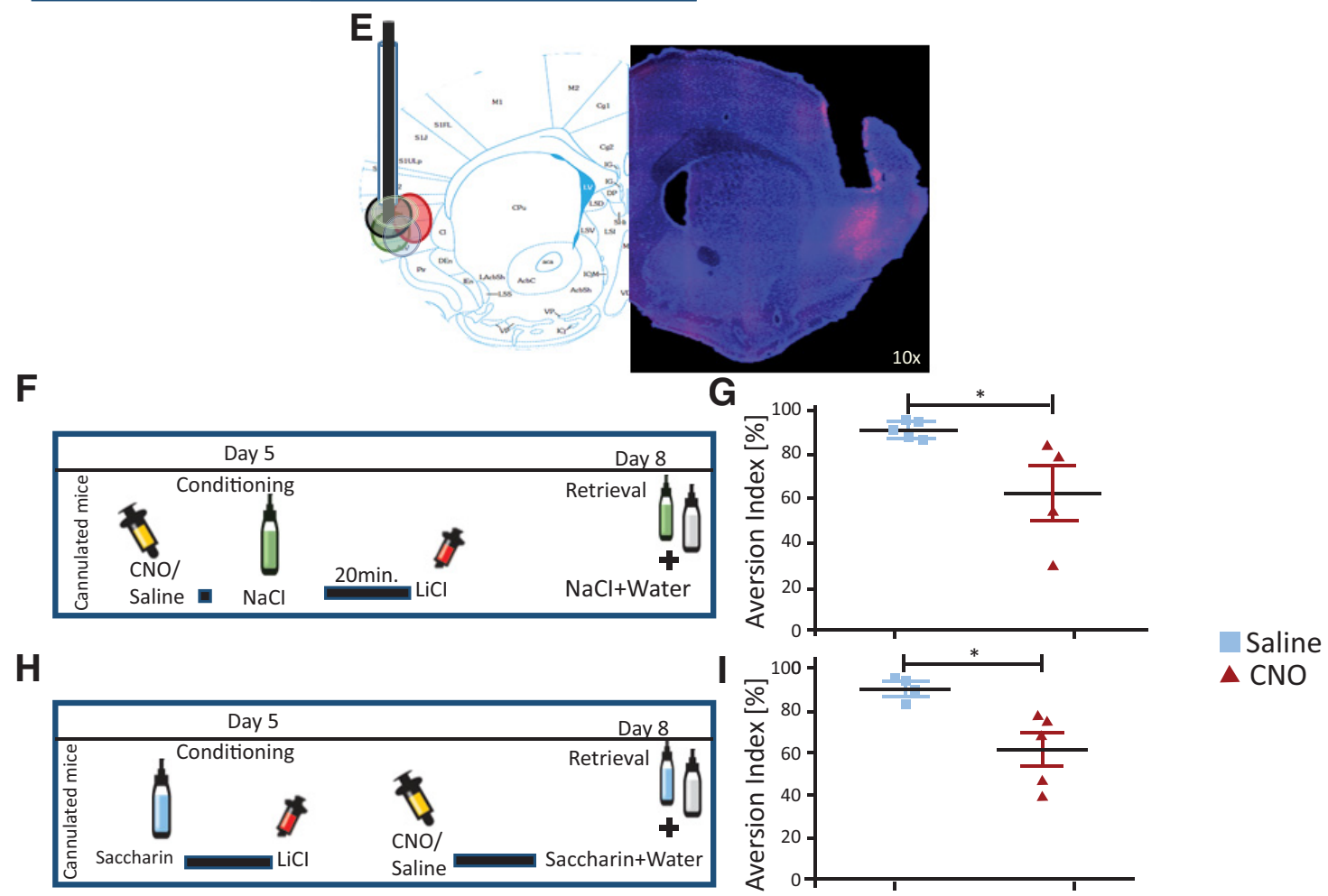

Figure 5. Chemogenetic inhibition of IC-BLA-projecting neurons of the alC through local CNO administration at the alC disrupts CTA memory acquisition and retrieval. Adult male mice were injected with viral constructs at the alC and BLA, resulting in the expression of mCherry, without DREADD receptors (see Materials and Methods). Mice treated in this fashion received CN0 either before the acquisition or before retrieval of $\mathrm{CTA}(\boldsymbol{A})$. Control virus treated mice receiving CNO and mice expressing chemogenetic receptors in the alC-to-BLA projection but receiving saline before CTA acquisition or retrieval, exhibit no significant effect differences due to treatment or as a consequence of the retrieval and acquisition protocols $(\boldsymbol{B})$. A separate set of mice that were treated in this fashion, and received CNO while expanding the interstimulus interval for CTA to examine CS- and US-specific effects (C). Aversion in CNO and saline groups was similar (D). In a separate group of mice, DREADD receptors were introduced in the projection and guide cannulas were placed at the IC, allowing for local inhibition of the circuit, limiting the influence of collateralization $(\boldsymbol{E})$. Diagrammatic representation of cannula placement at the alC, as well as overlays of mean DREADD expression in cannulated mice, as indicated by mCherry ${ }^{+}$neurons $(\boldsymbol{E})$. Inhibition of the projection either during the acquisition $(\boldsymbol{F}, \boldsymbol{G})$ or during the retrieval of $\mathrm{CTA}(\boldsymbol{H}, \boldsymbol{I})$ significantly suppressed aversion to the $C S$ regardless of stimulus identity. ${ }^{*} p \leq 0.05$.

the intervention during conditioning, $\mathrm{CNO}(62.58 \pm 12.525 \%$, $n=4)$ treated mice showed a significant impairment in aversion compared with saline $(91.40 \pm 1.55 \%, n=5)$ treated mice (Fig. $5 G$, unpaired $t$ test, $p=0.0361, t=2.587, \mathrm{DF}=7)$. When examining the intervention during the retrieval of the memory (Fig. $5 \mathrm{H}, \mathrm{I}$, unpaired $t$ test, $p=0.0165, t=3.133, \mathrm{DF}=7$ ), aIC-to-BLA inhibited mice showed a reduction in aversion $(61.84 \pm 7.663 \%, n=5)$ compared with their controls $(90.20 \pm 2.888 \%, n=4)$. In summary, these results indicate that IC-BLA projections underlie the encoding of malaise (i.e.US) or the association between tastes and unwanted effects of a perceived US. We thus tested the hypothesis that activation of the pathway is sufficient to serve as an artificial US. 


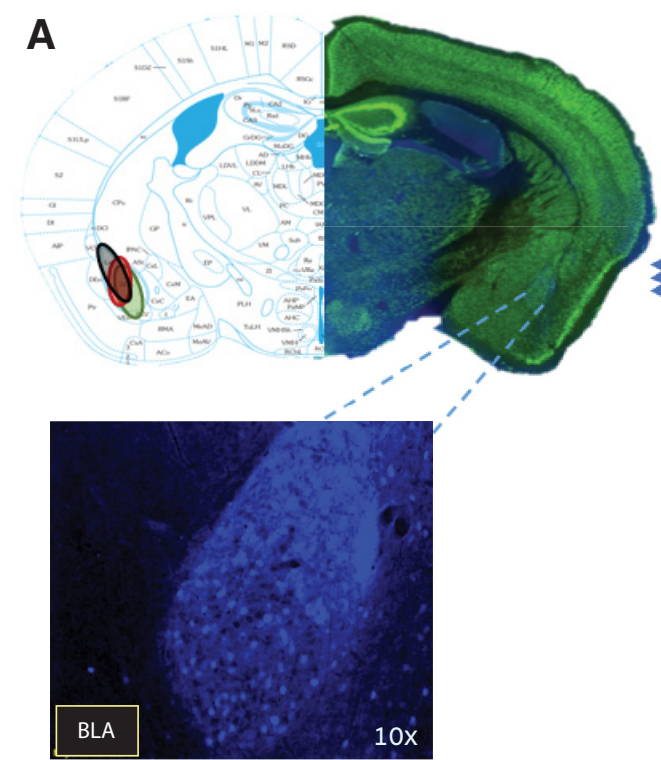

B

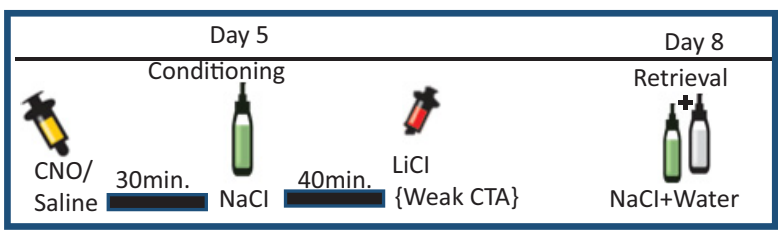

D

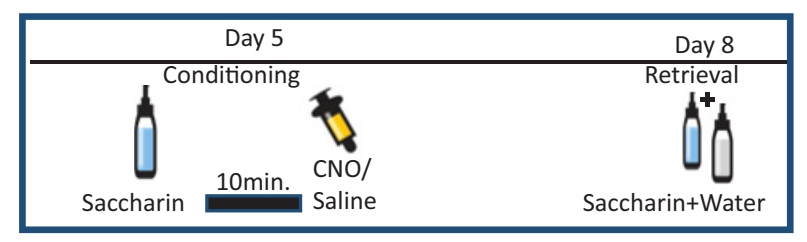

$\mathbf{F}$

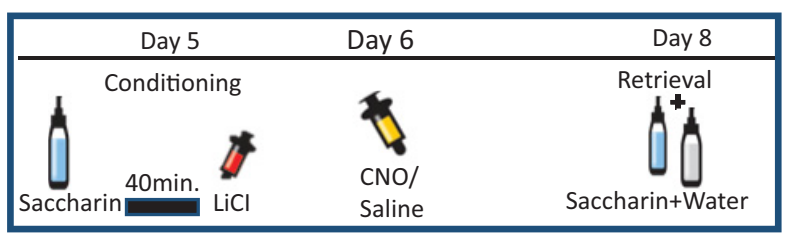

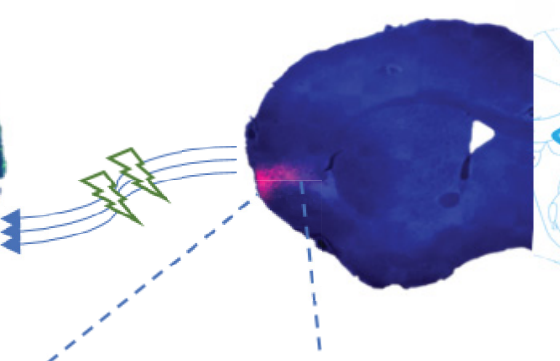
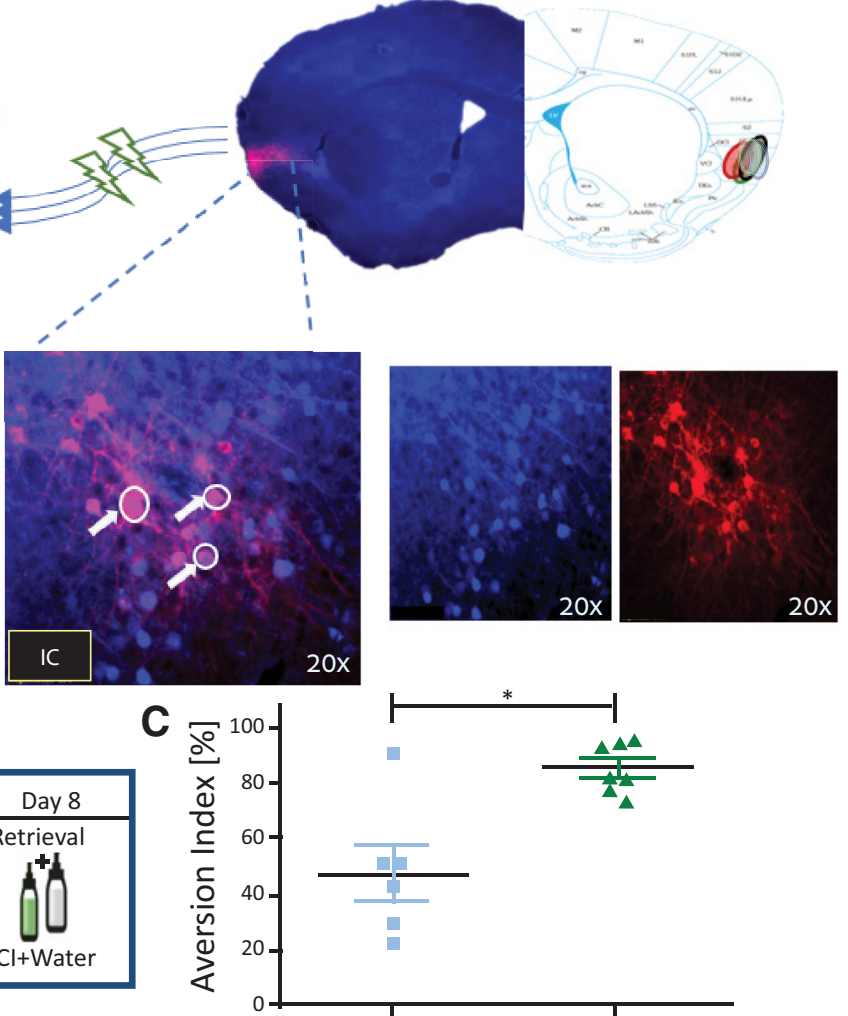

E

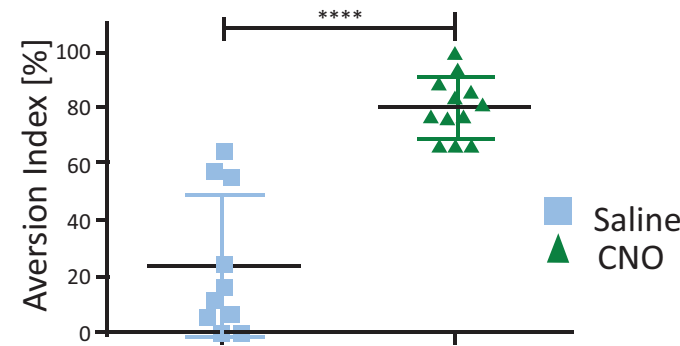

G

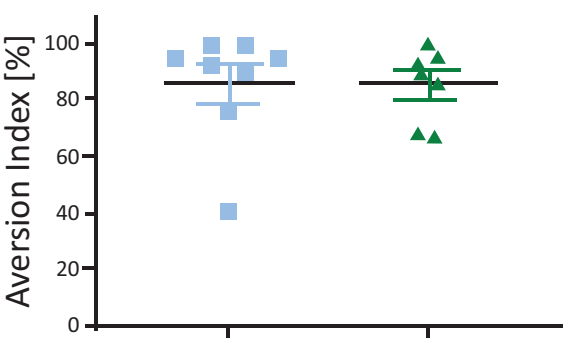

Figure 6. Activation of IC-to-BLA projecting neurons after the sampling of a novel taste is sufficient to form an artificial aversive taste memory. WT male mice were injected with viral constructs at the BLA and aIC, resulting in Cre-dependent expression of activating hMD3Gq tethered to mCherry in BLA projecting neurons of the alC $(\boldsymbol{A})$. Representative schematic overlays of the $C$ re-dependent expression of the chemogenetic receptors using the retroAAV systems is shown, demonstrating the expression to be restricted in the BLA and alC ( $n=12$ slices). After recovery, animals were split into groups receiving either saline (light blue) or CNO (green) $30 \mathrm{~min}$ before weak CTA training, followed by a retrieval choice test as described in (B). Chemogenetic activation of the projection using CNO (B) significantly enhanced the expressed aversion compared with control animals $(\boldsymbol{C})$. We then tested whether chemogenetic activation of the IC-to-BLA projecting neurons after novel taste learning in mice, is sufficient to induce the expression of aversive taste behavior upon retrieval testing (D). Activation of the projection by administering CNO immediately after novel taste learning resulted in significant aversion in treated mice compared with control animals $(\boldsymbol{E})$. To examine whether activation of alC-to-BLA projecting neurons affects the maintenance of memory, in similarly injected animals, we activated the projection using CNO, $24 \mathrm{~h}$ after weak CTA training $(\boldsymbol{F})$. Nonetheless, the mean aversion to the CS in the CN0 and saline (G) groups was similar after this intervention. ${ }^{*} p \leq 0.05$.

\section{Activation of IC-to-BLA projecting neurons after the} sampling of a novel taste is sufficient to form an artificial aversive taste memory

To interrogate the validity of our hypothesis that activation of IC-to-BLA projecting neurons is sufficient for the expression of aversive taste behavior, mice were injected with AAV constructs, resulting in expression of the activating chemogenetic receptor (hM3DGq) tethered to mCherry in the projection (Fig. 6A; see Materials and Methods). Artificial activation of BLA-projecting neurons of the aIC during weak CTA conditioning (Fig. $6 B, C$, 
unpaired $t$ test, $p<0.0001, t=5.869, \mathrm{DF}=18$ ), significantly increased aversion $(86.08 \pm 2.847 \%, n=10)$ to the conditioned tastant, compared with control $(44.13 \pm 6.555 \%, n=10)$ animals. To examine whether activity within the IC-to-BLA pathway is sufficient for the formation of an aversive taste memory, a separate group of mice consumed a novel tastant (saccharin) followed by activation of the projection immediately afterward (Fig. $6 D$, CNO $80.78 \pm 3.064 \%, n=12$; saline $24.24 \pm 8.015 \%$, $n=10$ ), without receiving a malaise-inducing US (i.e., no visceral experience). This resulted in strong aversive behavior during the retrieval test (Fig. $6 E$, unpaired $t$ test, $p<0.0001, t=7.053$, DF $=$ 20). Conversely, activation of the projection $24 \mathrm{~h}$ after weak conditioning (Fig. $6 F$ ) resulted in similar aversion between control $(86.3 \pm 7.100 \%, n=8)$ and CNO-treated mice (85.67 \pm 4.912 , $n=7$ ) upon retrieval testing $48 \mathrm{~h}$ later (Fig. $6 G, p=0.9444, t=$ $0.07109, \mathrm{DF}=13)$, indicating that the influence of the projection does not extend to processes facilitating memory maintenance. In summary, our results demonstrate that activation of the ICBLA pathway minutes after novel taste consumption is sufficient and necessary for the encoding and enhancement of inputs allowing for the association of CS and US during learning and is reactivated to guide behavior during retrieval.

\section{Discussion}

Reciprocal connections of the anterior and posterior IC with the amygdala complex have been heavily implicated in rewardrelated encoding of both innate and learned (Stone et al., 2011; Jezzini et al., 2013; Haley et al., 2016). CTA acquisition results in a concerted bidirectional interplay of activity (Escobar and Bermúdez-Rattoni, 2000), posttranslation regulation (Adaikkan and Rosenblum, 2012), protein synthesis (Levitan et al., 2016; Guzmán-Ramos et al., 2018), as well as transcription (Inberg et al., 2016) and histone deacetylation (Rodríguez-Blanco et al., 2019), at the two regions. Though a number of gustatory relay stations undergo changes in activity and plasticity markers (Lamprecht and Dudai, 1995; Rosenblum et al., 1997; Swank, 1999), the aIC is unique in that its inactivation produces deficits in acquisition (Buresová, 1978; Gallo and Bures, 1991), and prominently suppresses CTA retrieval (Yasoshima et al., 2000; Yasoshima and Yamamoto, 2005; Gal-Ben-Ari and Rosenblum, 2011).

Studies using CTA and other outcome devaluation models have since demonstrated that excitatory aIC neurons are necessary for the acquisition of learned aversive memories, but also the expression of nonhomeostatic, valence-driven choice behaviors (Adaikkan and Rosenblum, 2015; Parkes et al., 2015; Baldo et al., 2016; Rogers-Carter et al., 2018). The DI and AI subregions integrate chemosensory, somatosensory, visceral and limbic information into a complex temporal code (Katz et al., 2001; Jones et al., 2006; Yokota et al., 2011), which provides the encoding framework for associative relationships between experience and outcome (Gardner and Fontanini, 2014; Haley and Maffei, 2018). The aIC is thus increasingly viewed as a center dedicated to the fine-tuning of behavior to salient sensory-reward/aversive associations, rather than a chemosensory center in the broader sense (Stehberg and Simon, 2011; Baldo et al., 2016; Fletcher et al., 2017; Fonseca et al., 2018; Inui et al., 2019).

Presentation of the CS for CTA induces marked ERK activation in both the IC and BLA (Berman, 2003; Lin et al., 2010) and activation of BLA projections to reward centers (Inui et al., 2013). However, electrophysiological activity is inhibited in the majority of recorded BLA units in vivo (Uwano et al., 1995; Kim et al., 2010), Nonetheless, electrophysiological and molecular changes within excitatory BLA neurons have indeed been reported in a number of studies examining CTA acquisition and retrieval (Yasoshima and Yamamoto, 2005; Barot et al., 2008; GuzmanRamos and Bermudez-Rattoni, 2012; Osorio-Gómez et al., 2017). Perhaps, despite their activation during acquisition, only a small proportion of BLA neurons is reactivated during retrieval, while the contribution of fibers projecting through or away from the BLA is indeed significant (Dunn and Everitt, 1988; Bahar et al., 2004; Inui et al., 2019).

We have previously demonstrated using in vivo two-photon $\mathrm{Ca}^{2+}$ imaging of the aIC in mice, that CTA retrieval increases recruitment of the IC-BLA pathway, in a valence- and not stimulus-specific manner (Lavi et al., 2018). To further address the role of this projection in the expression of valence-specific behaviors, we first attempted to better define its spatial distribution (Fig. 1), by imaging the extended aIC in mice injected with retroAAV at the BLA (Tervo et al., 2016). We found that consistent with the literature (Krushel and van Der Kooy, 1988; Kobayashi, 2011; Gogolla, 2017), BLA-projecting neurons primarily reside within deep layers of the AI and DI (Fig. $1 B-D$ ). We then confirmed that infected cells at injection sites were limited to the BLA, and that projecting neurons can be chemogenetically manipulated through the Cre-dependent expression of DREADDs at the aIC (Fig. 2).

The bidirectional connectivity of the aIC with the BLA has been suggested to be key in shaping the perceived valence of sensory experiences through integrating the CS with subjective visceral and emotional experiences (Shi and Cassell, 1998; Maffei et al., 2012; Avery et al., 2017). We therefore hypothesized that recruitment of the projection subserves the encoding of negative internal body states (e.g., malaise induced by an US), but also facilitates their association with taste stimuli (e.g., saccharin), guiding the expression of appropriate behavioral responses upon retrieval (Höistad and Barbas, 2008; Craig, 2009). We tested our hypothesis by inhibiting or activating the projection during two different behavioral paradigms: the associative, negative learning paradigm of CTA and the incidental, positive learning paradigm of novel taste learning (Figs. 3, 4, 5, 6). Indeed, inhibition of the projection during CTA acquisition and retrieval using intraperitoneal or local CNO injections (Figs. 3, 5), resulted in significantly suppressed aversion to the CS upon choice testing, in support of previous findings (Lavi et al., 2018).

Furthermore, chemogenetic activation of the aIC-to-BLA pathway during weak conditioning enhanced aversive memory retrieval, and was surprisingly sufficient to drive the expression aversion to the CS in the absence of a real US sensory experience (Fig. $6 B-E$ ). In agreement with the above, inhibition during the CS- or US-encoding phase of CTA acquisition significantly suppressed learned aversive behavior, but did not affect innate taste behaviors (Fig. $4 A, B$ ). Importantly, inhibition during retrieval did not lead to faster extinction (Fig. $3 \mathrm{H}, I$ ), while neither inhibition nor activation of the projection affected memory maintenance (Figs. $3 F, G, 6 F, G$ ), suggesting that the manipulation itself does not permanently change or damage the neurons involved. We thus propose that during CTA acquisition, activation of the aIC-to-BLA projection facilitates CS-US associations, shapes the valence encoding to learned taste experiences, and is reactivated to enable the retrieval of past learned associations (Small et al., 2003; Fontanini et al., 2009; Piette et al., 2012). Inhibition of aIC-to-BLA neurons using local CNO delivery at the aIC further confirmed the necessity of the projection for CTA memory acquisition and expression (Fig. 5E-I), while suggesting that its recruitment acts upstream of BLA collaterals to reward centers 
(Dunn and Everitt, 1988; Juárez-Muñoz et al., 2017; Inui et al., 2019). Nonetheless, it is possible that aIC collaterals of the projection to other regions might also contribute to the effects elicited by chemogenetic interventions (Wright and Groenewegen, 1996; Reynolds and Zahm, 2005; Stachniak et al., 2014).

Projections of the posterior IC to the central amygdala (CeA) have been reported to shape and reverse, upon manipulation, the valence of innate stimulus-specific responses to bitter tastants (Schiff et al., 2018; Wang et al., 2018), while the anterior rostral IC-to-BLA projection has been implicated in innate appetitive behaviors to sweet taste (Wang et al., 2018). Our findings do not preclude these circuits being involved in innate taste responses, as we focused on learned aversive behaviors and BLA-projecting neurons in portions of the region that were not examined in the aforementioned studies (Schiff et al., 2018; Wang et al., 2018). Moreover, the apparent discrepancy (Wang et al., 2018), might be further explained by reports demonstrating a shift of the spatial arrangement of aIC responses across the posterior axis after CTA acquisition in a valence-specific manner, resembling innate aversive responses (Accolla and Carleton, 2008; Carleton et al., 2010; Lavi et al., 2018). However, even though manipulation of the aIC-to-BLA projection does not affect innate taste responses, other aIC circuits engaged in such innate responses, might contribute to CTA learning and retrieval (Bales et al., 2015; Schiff et al., 2018; Inui et al., 2019). On the other hand, given the multimodal role of the insula, perhaps spatial overlapping between circuits subserving innate and learned behaviors of opposing valence, might not necessarily constitute a discrepancy (Ohla et al., 2019). For example, a recent study characterized a distinct Nos1expressing IC-to-CeA projection that is necessary for learned food overconsumption, but not for homeostatic feeding (Stern et al., 2019). Activity and connectivity within complex neocortical structures such as the insula, might not operate merely under spatial segregation rules, and perhaps the role of certain circuits should be more carefully considered in relation their distinct molecular characteristics, among others (Grant, 2018).

To examine whether aIC-to-BLA neurons are also involved in the retrieval of other types of memory, we inhibited the projection during fear memory retrieval. However, chemogenetic inhibition (Gomez et al., 2017) failed to affect freezing behavior in conditioned mice (Fig. 4G,H). As other recent studies indicate, distinct amygdala-projecting neurons in the posterior IC (pIC) are more prominently involved (Grewe et al., 2017; Berret et al., 2019). Interestingly, even though this pIC projection participates in multiple stages during memory formation and retrieval (Berret et al., 2019), distinct CeA-projecting neurons drive acute freezing behavior, without leaving a memory trace (Grewe et al., 2017). Even so, we cannot rule out the possibility that the aIC-to-BLA projection participates in fear memory acquisition, or other types of learning and memory (Parkes and Balleine, 2013; RogersCarter et al., 2018). The aIC has been implicated in self-referential processes, and our results further suggest learned aversive behavior to arise, at least in part, through changes in activity and connectivity of the region in relation to internal, subjective states (Critchley and Seth, 2012; Pais-Vieira et al., 2016). The aIC-toBLA projection is necessary for CS-US association during CTA acquisition, and is subsequently reactivated to guide retrieval, likely consequent to brain-wide adaptations necessary for memory maintenance (Smolen et al., 2019). Future studies should dissect the role of aIC connectivity and distinct cell types in taste memory encoding, maintenance and retrieval more comprehensively.

\section{References}

Accolla R, Carleton A (2008) Internal body state influences topographical plasticity of sensory representations in the rat gustatory cortex. Proc Natl Acad Sci U S A 105:4010-4015.

Adaikkan C, Rosenblum K (2012) The role of protein phosphorylation in the gustatory cortex and amygdala during taste learning. Exp Neurobiol 21:37-51.

Adaikkan C, Rosenblum K (2015) A molecular mechanism underlying gustatory memory trace for an association in the insular cortex. Elife 4:e07582.

Alapin JM, Dines M, Vassiliev M, Tamir T, Ram A, Locke C, Yu J, Lamprecht R (2018) Activation of EphB2 forward signaling enhances memory consolidation. Cell Rep 23:2014-2025.

Avery JA, Gotts SJ, Kerr KL, Burrows K, Ingeholm JE, Bodurka J, Martin A, Kyle Simmons W (2017) Convergent gustatory and viscerosensory processing in the human dorsal mid-insula. Hum Brain Mapp 38:2150-2164.

Bahar A, Dorfman N, Dudai Y (2004) Amygdalar circuits required for either consolidation or extinction of taste aversion memory are not required for reconsolidation. Eur J Neurosci 19:1115-1118.

Baldo BA, Spencer RC, Sadeghian K, Mena JD (2016) GABA-mediated inactivation of medial prefrontal and agranular insular cortex in the rat: contrasting effects on hunger-and palatability-driven feeding. Neuropsychopharmacology 41:960-970.

Bales MB, Schier LA, Blonde GD, Spector AC (2015) Extensive gustatory cortex lesions significantly impair taste sensitivity to $\mathrm{KCl}$ and quinine but not to sucrose in rats. PLoS One 10:e0143419.

Barot SK, Kyono Y, Clark EW, Bernstein IL (2008) Visualizing stimulus convergence in amygdala neurons during associative learning. Proc Natl Acad Sci U S A 105:20959-20963.

Belelovsky K, Elkobi A, Kaphzan H, Nairn AC, Rosenblum K (2005) A molecular switch for translational control in taste memory consolidation. Eur J Neurosci 22:2560-2568.

Berman DE (2003) Modulation of taste-induced elk-1 activation by identified neurotransmitter systems in the insular cortex of the behaving rat. Neurobiol Learn Mem 79:122-126.

Bermudez-Rattoni F (2014) The forgotten insular cortex: Its role on recognition memory formation. Neurobiol Learn Mem 109:207-216.

Berret E, Kintscher M, Palchaudhuri S, Tang W, Osypenko D, Kochubey O, Schneggenburger R (2019) Insular cortex processes aversive somatosensory information and is crucial for threat learning. Science 364:eaaw0474.

Bures J, Bermúdez-Rattoni F, Yamamoto T (1998) Conditioned taste aversion: Memory of a Special Kind. pp 14-25. New York: Oxford University Press.

Buresová O (1978) Neocortico-amygdalar interaction in the conditioned taste aversion in rats. Act Nerv Super (Praha) 20:224-230.

Burnett CJ, Krashes MJ (2016) Resolving behavioral output via chemogenetic designer receptors exclusively activated by designer drugs. J Neurosci 36:9268-9282.

Caria A, Sitaram R, Veit R, Begliomini C, Birbaumer N (2010) Volitional control of anterior insula activity modulates the response to aversive stimuli: a real-time functional magnetic resonance imaging study. Biol Psychiatry 68:425-432.

Carleton A, Accolla R, Simon SA (2010) Coding in the mammalian gustatory system. Trends Neurosci 33:326-334.

Cechetto DF, Saper CB (1987) Evidence for a viscerotopic sensory representation in the cortex and thalamus in the rat. J Comp Neurol 262:27-45.

Craig AD (2009) How do you feel-now? The anterior insula and human awareness. Nat Rev Neurosci 10:59-70.

Critchley H, Seth A (2012) Will studies of macaque insula reveal the neural mechanisms of self-awareness? Neuron 74:423-426.

Curzon P, Rustay N, Browman K (2009) Cued and Contextual Fear Conditioning for Rodents. In: Methods of Behavior Analysis in Neuroscience, Ed 2 (Buccafusco JJ, ed). Boca Raton (FL): CRC Press/Taylor \& Francis.

Dunn LT, Everitt BJ (1988) Double dissociations of the effects of amygdala and insular cortex lesions on conditioned taste aversion, passive avoidance, and neophobia in the rat using the excitotoxin ibotenic acid. Behav Neurosci 102:3-23.

Escobar ML, Bermúdez-Rattoni F (2000) Long-term potentiation in the insular cortex enhances conditioned taste aversion retention. Brain Res 852:208-212.

Fletcher ML, Ogg MC, Lu L, Ogg RJ, Boughter JD Jr (2017) Overlapping 
representation of primary tastes in a defined region of the gustatory cortex. J Neurosci 37:7595-7605.

Fonseca E, de Lafuente V, Simon SA, Gutierrez R (2018) Sucrose intensity coding and decision-making in rat gustatory cortices. Elife 7:e41152.

Fontanini A, Katz DB (2009) Behavioral modulation of gustatory cortical activity. Ann N Y Acad Sci 1170:403-406.

Fontanini A, Grossman SE, Figueroa JA, Katz DB (2009) Distinct subtypes of basolateral amygdala taste neurons reflect palatability and reward. J Neurosci 29:2486-2495.

Gal-Ben-Ari S, Rosenblum K (2011) Molecular mechanisms underlying memory consolidation of taste information in the cortex. Front Behav Neurosci 5:87.

Gallo M, Bures J (1991) Acquisition of conditioned taste aversion in rats is mediated by ipsilateral interaction of cortical and mesencephalic mechanisms. Neurosci Lett 133:187-190.

Garcia J, Kimeldorf DJ, Koelling RA (1955) Conditioned aversion to saccharin resulting from exposure to gamma radiation. Science 122:157-158.

Gardner MP, Fontanini A (2014) Encoding and tracking of outcomespecific expectancy in the gustatory cortex of alert rats. J Neurosci 34: $13000-13017$.

Gogolla N (2017) The insular cortex. Curr Biol 27:R580-R586.

Gomez JL, Bonaventura J, Lesniak W, Mathews WB, Sysa-Shah P, Rodriguez LA, Ellis RJ, Richie CT, Harvey BK, Dannals RF, Pomper MG, Bonci A, Michaelides M (2017) Chemogenetics revealed: DREADD occupancy and activation via converted clozapine. Science 357:503-507.

Grant SGN (2018) The synaptomic theory of behavior and brain disease. Cold Spring Harb Symp Quant Biol 83:45-56.

Grewe BF, Gründemann J, Kitch LJ, Lecoq JA, Parker JG, Marshall JD, Larkin MC, Jercog PE, Grenier F, Li JZ, Lüthi A, Schnitzer MJ (2017) Neural ensemble dynamics underlying a long-term associative memory. Nature 543:670-675.

Grossman SE, Fontanini A, Wieskopf JS, Katz DB (2008) Learning-related plasticity of temporal coding in simultaneously recorded amygdalacortical ensembles. J Neurosci 28:2864-2873.

Guzman-Ramos K, Bermudez-Rattoni F (2012) Interplay of amygdala and insular cortex during and after associative taste aversion memory formation. Rev Neurosci 23:463-471.

Guzmán-Ramos K, Venkataraman A, Morin JP, Osorio-Gómez D, Bermúdez-Rattoni F (2018) Differential requirement of de novo Arc protein synthesis in the insular cortex and the amygdala for safe and aversive taste long-term memory formation. Behav Brain Res 342:89-93.

Haley MS, Maffei A (2018) Versatility and flexibility of cortical circuits. Neuroscientist 24:456-470.

Haley MS, Fontanini A, Maffei A (2016) Laminar- and target-specific amygdalar inputs in rat primary gustatory cortex. J Neurosci 36:26232637.

Höistad M, Barbas H (2008) Sequence of information processing for emotions through pathways linking temporal and insular cortices with the amygdala. Neuroimage 40:1016-1033.

Inberg S, Jacob E, Elkobi A, Edry E, Rappaport A, Simpson TI, Armstrong JD, Shomron N, Pasmanik-Chor M, Rosenblum K (2016) Fluid consumption and taste novelty determines transcription temporal dynamics in the gustatory cortex. Mol Brain 9:13.

Inui T, Inui-Yamamoto C, Yoshioka Y, Ohzawa I, Shimura T (2013) Activation of efferents from the basolateral amygdala during the retrieval of conditioned taste aversion. Neurobiol Learn Mem 106:210-220.

Inui T, Sugishita T, Inui-Yamamoto C, Yasoshima Y, Shimura T (2019) The Basolateral Nucleus of the Amygdala Executes the Parallel Processes of Avoidance and Palatability in the Retrieval of Conditioned Taste Aversion in Male Rats. eNeuro 10:6.

Jezzini A, Mazzucato L, La Camera G, Fontanini A (2013) Processing of hedonic and chemosensory features of taste in medial prefrontal and insular networks. J Neurosci 33:18966-18978.

Jones LM, Fontanini A, Katz DB (2006) Gustatory processing: a dynamic systems approach. Curr Opin Neurobiol 16:420-428.

Juárez-Muñoz Y, Ramos-Languren LE, Escobar ML (2017) CaMKII Requirement for in vivo insular cortex LTP maintenance and CTA memory persistence. Front Pharmacol 8:822.

Katz DB, Simon SA, Nicolelis MA (2001) Dynamic and multimodal responses of gustatory cortical neurons in awake rats. J Neurosci 21:44784489.

Kim MJ, Mizumori SJ, Bernstein IL (2010) Neuronal representation of con- ditioned taste in the basolateral amygdala of rats. Neurobiol Learn Mem 93:406-414.

Kobayashi M (2011) Macroscopic connection of rat insular cortex: anatomical bases underlying its physiological functions. Int Rev Neurobiol 97:285-303.

Kosar E, Grill HJ, Norgren R (1986) Gustatory cortex in the rat. I. Physiological properties and cytoarchitecture. Brain Res 379:329-341.

Krushel LA, van der Kooy D (1988) Visceral cortex: Integration of the mucosal senses with limbic information in the rat agranular insular cortex. J Comp Neurol 270:39-54, 62-3.

Kurth F, Zilles K, Fox PT, Laird AR, Eickhoff SB (2010) A link between the systems: functional differentiation and integration within the human insula revealed by meta-analysis. Brain Struct Funct 214:519-534.

Lamprecht R, Dudai Y (1995) Differential modulation of brain immediate early genes by intraperitoneal LiCl. NeuroReport 7:289-293.

Lavi K, Jacobson GA, Rosenblum K, Lüthi A (2018) Encoding of conditioned taste aversion in cortico-amygdala circuits. Cell Rep 24:278-283.

Levitan D, Gal-Ben-Ari S, Heise C, Rosenberg T, Elkobi A, Inberg S, Sala C, Rosenblum K (2016) The differential role of cortical protein synthesis in taste memory formation and persistence. NPJ Sci Learn 1:16001.

Lin JY, Arthurs J, Reilly S (2015) Gustatory insular cortex, aversive taste memory and taste neophobia. Neurobiology of Learning and Memory 119:77-84.

Lin PY, Wang SP, Tai MY, Tsai YF (2010) Differential involvement of medial prefrontal cortex and basolateral amygdala extracellular signalregulated kinase in extinction of conditioned taste aversion is dependent on different intervals of extinction following conditioning. Neuroscience 171:125-133.

Maffei A, Haley M, Fontanini A (2012) Neural processing of gustatory information in insular circuits. Curr Opin Neurobiol 22:709-716.

Merhav M, Kuulmann-Vander S, Elkobi A, Jacobson-Pick S, Karni A, Rosenblum K (2006) Behavioral interference and C/EBPbeta expression in the insular-cortex reveal a prolonged time period for taste memory consolidation. Learn Mem 13:571-574.

Moraga-Amaro R, Stehberg J (2012) The Insular Cortex and the Amygdala: Shared Functions and Interactions. In: The Amygdala - A Discrete Multitasking Manager (Ferry B, ed), pp 231-256. London: InTechOpen.

Nakajima K, Cui Z, Li C, Meister J, Cui Y, Fu O, Smith AS, Jain S, Lowell BB, Krashes MJ, Wess J (2016) Gs-coupled GPCR signalling in AgRP neurons triggers sustained increase in food intake. Nat Commun 7:10268.

Ohla K, Yoshida R, Roper SD, Di Lorenzo PM, Victor JD, Boughter JD, Fletcher M, Katz DB, Chaudhari N (2019) Recognizing taste: coding patterns along the neural axis in mammals. Chem Senses 44:237-247.

Osorio-Gómez D, Guzmán-Ramos K, Bermúdez-Rattoni F (2017) Memory trace reactivation and behavioral response during retrieval are differentially modulated by amygdalar glutamate receptors activity: interaction between amygdala and insular cortex. Learn Mem 24:14-23.

Pais-Vieira C, Wing EA, Cabeza R (2016) The influence of self-awareness on emotional memory formation: An fMRI study. Soc Cogn Affect Neurosci 11:580-592.

Parkes SL, Balleine BW (2013) Incentive memory: evidence the basolateral amygdala encodes and the insular cortex retrieves outcome values to guide choice between goal-directed actions. J Neurosci 33:8753-8763

Parkes SL, Bradfield LA, Balleine BW (2015) Interaction of insular cortex and ventral striatum mediates the effect of incentive memory on choice between goal-directed actions. J Neurosci 35:6464-6471.

Piette CE, Baez-Santiago MA, Reid EE, Katz DB, Moran A (2012) Inactivation of basolateral amygdala specifically eliminates palatability-related information in cortical sensory responses. J Neurosci 32:9981-9991.

Reynolds SM, Zahm DS (2005) Specificity in the projections of prefrontal and insular cortex to ventral striatopallidum and the extended amygdala. J Neurosci 25:11757-11767.

Rodríguez-Blanco LA, Rivera-Olvera A, Escobar ML (2019) Consolidation of an aversive taste memory requires two rounds of transcriptional and epigenetic regulation in the insular cortex. Behav Brain Res 356:371-374.

Rogers-Carter MM, Varela JA, Gribbons KB, Pierce AF, McGoey MT, Ritchey M, Christianson JP (2018) Insular cortex mediates approach and avoidance responses to social affective stimuli. Nat Neurosci 21:404-414.

Rosenblum K (2008) Conditioned taste aversion and taste learning: molecular mechanisms. In: Concise learning and memory: the editors selection (Byrne JH, ed), pp 465-479. Amsterdam: Elsevier. 
Rosenblum K, Meiri N, Dudai Y (1993) Taste memory: The role of protein synthesis in gustatory cortex. Behav Neural Biol 59:49-56.

Rosenblum K, Berman DE, Hazvi S, Lamprecht R, Dudai Y (1997) NMDA receptor and the tyrosine phosphorylation of its $2 \mathrm{~B}$ subunit in taste learning in the rat insular cortex. J Neurosci 17:5129-5135.

Schiff HC, Bouhuis AL, Yu K, Penzo MA, Li H, He M, Li B (2018) An insula-central amygdala circuit for guiding tastant-reinforced choice behavior. J Neurosci 38:1418-1429.

Sharma V, Ounallah-Saad H, Chakraborty D, Hleihil M, Sood R, Barrera I, Edry E, Kolatt Chandran S, Ben Tabou de Leon S, Kaphzan H, Rosenblum K (2018) Local inhibition of PERK enhances memory and reverses agerelated deterioration of cognitive and neuronal properties. J Neurosci 38:648-658.

Shi CJ, Cassell MD (1998) Cortical, thalamic, and amygdaloid connections of the anterior and posterior insular cortices. J Comp Neurol 399: $440-468$.

Small DM, Gregory MD, Mak YE, Gitelman D, Mesulam MM, Parrish T (2003) Dissociation of neural representation of intensity and affective valuation in human gustation. Neuron 39:701-711.

Smolen P, Baxter DA, Byrne JH (2019) How Can Memories Last for Days, Years, or a Lifetime? Proposed Mechanisms for Maintaining Synaptic Potentiation and Memory. Learn Mem 26:133-150.

Stachniak TJ, Ghosh A, Sternson SM (2014) Chemogenetic synaptic silencing of neural circuits localizes a hypothalamus $\rightarrow$ midbrain pathway for feeding behavior. Neuron 82:797-808.

Stehberg J, Simon F (2011) Involvement of the insular cortex in retention of conditioned taste aversion is not time dependent. Neurobiol Learn Mem 95:14-18.

Stern SAA, Pomeranz LEE, Azevedo EPP, Doerig KRR, Friedman JMM (2019) A molecularly defined insular cortex $\rightarrow$ central amygdala circuit mediates. bioRxiv. Available at: https://www.biorxiv.org/content/10. $1101 / 684498 \mathrm{v} 1$.

Stone ME, Maffei A, Fontanini A (2011) Amygdala stimulation evokes time-varying synaptic responses in the gustatory cortex of anesthetized rats. Front Integr Neurosci 5:3.
Swank MW (1999) Coordinate regulation of Fos and Jun proteins in mouse brain by LiCl. Neuroreport 10:3685-3689.

Tervo DG, Hwang BY, Viswanathan S, Gaj T, Lavzin M, Ritola KD, Lindo S, Michael S, Kuleshova E, Ojala D, Huang CC, Gerfen CR, Schiller J, Dudman JT, Hantman AW, Looger LL, Schaffer DV, Karpova AY (2016) A designer AAV variant permits efficient retrograde access to projection neurons. Neuron 92:372-382.

Tye KM (2018) Neural circuit motifs in valence processing. Neuron 100:436-452.

Uwano T, Nishijo H, Ono T, Tamura R (1995) Neuronal responsiveness to various sensory stimuli, and associative learning in the rat amygdala. Neuroscience 68:339-361.

Wang L, Gillis-Smith S, Peng Y, Zhang J, Chen X, Salzman CD, Ryba NJP, Zuker CS (2018) The coding of valence and identity in the mammalian taste system. Nature 558:127-131.

Wright CI, Groenewegen HJ (1996) Patterns of overlap and segregation between insular cortical, intermediodorsal thalamic and basal amygdaloid afferents in the nucleus accumbens of the rat. Neuroscience 73:359-373.

Yasoshima Y, Yamamoto T (2005) Effects of midazolam on the expression of conditioned taste aversion in rats. Brain Res 1043(1-2):115-123.

Yasoshima Y, Morimoto T, Yamamoto T (2000) Different disruptive effects on the acquisition and expression of conditioned taste aversion by blockades of amygdalar ionotropic and metabotropic glutamatergic receptor subtypes in rats. Brain Res 869:15-24.

Yefet K, Merhav M, Kuulmann-Vander S, Elkobi A, Belelovsky K, JacobsonPick S, Meiri N, Rosenblum K (2006) Different signal transduction cascades are activated simultaneously in the rat insular cortex and hippocampus following novel taste learning. Eur J Neurosci 24:14341442.

Yiannakas A, Rosenblum K (2017) The insula and taste learning. Front Mol Neurosci 10:335

Yokota T, Eguchi K, Hiraba K (2011) Functional properties of putative pyramidal neurons and inhibitory interneurons in the rat gustatory cortex. Cereb Cortex 21:597-606. 